\title{
Aerodynamic and physical characterization of refuse derived fuel
}

Nakhaei, Mohammadhadi; Pedersen, Morten Nedergaard; Wu, Hao; Jensen, Lars Skaarup; Glarborg, Peter; Jensen, Peter Arendt; Grévain, Damien; Dam-Johansen, Kim

Published in:

Energy and Fuels

Link to article, DOI:

10.1021/acs.energyfuels.8b01359

Publication date:

2018

Document Version

Peer reviewed version

Link back to DTU Orbit

Citation (APA):

Nakhaei, M., Pedersen, M. N., Wu, H., Jensen, L. S., Glarborg, P., Jensen, P. A., Grévain, D., \& Dam-Johansen, $\mathrm{K}$. (2018). Aerodynamic and physical characterization of refuse derived fuel. Energy and Fuels, 32(7), 76857700. https://doi.org/10.1021/acs.energyfuels.8b01359

\section{General rights}

Copyright and moral rights for the publications made accessible in the public portal are retained by the authors and/or other copyright owners and it is a condition of accessing publications that users recognise and abide by the legal requirements associated with these rights.

- Users may download and print one copy of any publication from the public portal for the purpose of private study or research.

- You may not further distribute the material or use it for any profit-making activity or commercial gain

- You may freely distribute the URL identifying the publication in the public portal 


\title{
Aerodynamic and physical characterization of refuse derived fuel
}

\author{
Mohammadhadi Nakhaei, ${ }^{*, \dagger}$ Morten Nedergaard Pedersen, ${ }^{\dagger} \mathrm{Hao} \mathrm{Wu}^{*, \dagger}$ Lars \\ Skaarup Jensen, ${ }^{\ddagger}$ Peter Glarborg, ${ }^{\dagger}$ Peter Arendt Jensen, ${ }^{\dagger}$ Damien Grévain, ${ }^{\ddagger}$ and \\ Kim Dam-Johansen ${ }^{\dagger}$ \\ $\dagger$ Technical University of Denmark, Department of Chemical and Biochemical Engineering, \\ Søltofts Plads, Lyngby Campus, 2800 Kgs. Lyngby, Denmark \\ $\ddagger F L S m i d t h$ A/S, Cement RESD, Vigerslev Allé 77, 2500 Valby, Denmark \\ E-mail: mnak@kt.dtu.dk: haw@kt.dtu.dk
}

\begin{abstract}
Physical and aerodynamic characteristics of several refuse derived fuel (RDF) samples were studied. Each RDF sample was tested in a wind sieve to classify the particles into different fractions according to their terminal velocity. The individual particles from the wind sieve were then manually separated according to the material type and physically characterized by weight measurement and 2D photographing. For the tested samples, despite the overall weight distribution of the fractions from the wind sieve was similar, the material distribution of particles in each fraction was significantly different. It has been shown that regardless of the particle material, for each group of particles from the wind sieve test, the ratio of particle maximum projected area to particle mass lies in a narrow range. A new approach based on the particle maximum projected
\end{abstract}


area was proposed to predict the terminal velocity of particles and was tested for each group of particles from the wind sieve experiment. The maximum deviation of the mass-based averaged terminal velocity predicted from the drag model compared to the mid-point wind sieve velocity was smaller than $14 \%$. A procedure was proposed for physical characterization of RDF particles based on the wind sieve test and 2D imaging of particles. This characterization can be used as an input for Computational Fluid Dynamics (CFD) calculations of RDF-fired cement calciners and rotary kilns.

\section{Nomenclature}

$A_{p} \quad$ Particle projected area

$C_{D} \quad$ Drag coefficient

$d_{p} \quad$ Volume-equivalent particle diameter, $d_{p}=\left(\frac{6 V_{p}}{\pi}\right)^{1 / 3}$

$d_{m} \quad$ The $63^{\text {rd }}$ percentile of particle size or mass in Rosin-Rammler distribution

$D_{t} \quad$ Wind sieve tube diameter

$F_{D} \quad$ Drag force

$g \quad$ Gravity

$m_{p} \quad$ Particle mass

$n \quad$ Spreading parameter in Rosin-Rammler distribution

$R e_{p} \quad$ Particle Reynolds number, $R e_{p}=\rho_{g} d_{p} \frac{\left|\overrightarrow{U_{g}}-\overrightarrow{U_{p}}\right|}{\mu_{g}}$

$t_{p} \quad$ Particle thickness

$U_{g} \quad$ Gas velocity 
$U_{p} \quad$ Particle velocity

$V_{a} \quad$ Air velocity inside the wind sieve

$V_{p} \quad$ Particle volume

$V_{t} \quad$ Terminal velocity

$Y \quad$ Cumulative size or mass of Rosin-Rammler distribution

Greek symbols

$\mu_{g} \quad$ Gas viscosity

$\rho_{g} \quad$ Gas density

$\rho_{p} \quad$ Particle density

$\phi_{p} \quad$ Particle sphericity, $\phi_{p}=\frac{\pi d_{p}^{2}}{\text { Particle external surface area }}$

\section{Subscripts}

$\perp \quad$ Normal to the direction of relative velocity

\| Parallel to the direction of relative velocity

\section{Introduction}

In the past two decades, the use of alternative fuels has been significantly increased in the cement industry ${ }^{1}$ mainly because of reduced cost compared to the conventional fossil fuels. It is estimated that for the conventional cement plants, the fuel needed for production of 
one tonne of cement approximately costs 8 Euros. ${ }^{2}$ However, using waste derived fuels, e.g. Refuse Derived Fuel (RDF), Solid Recovered Fuel (SRF), etc., is less expensive or even free. ${ }^{2}$ In addition, the biomass fraction of these fuels is considered as $\mathrm{CO}_{2}-$ neutral, ${ }^{3}$ meaning that the net $\mathrm{CO}_{2}$ emission from combustion of biomass is zero. The overall $\mathrm{CO}_{2}$-neutrality of the waste--derived fuels depends on the amount of biomass-based fraction and fossil-based fraction (e.g. plastics) in the fuel.

RDF is produced from the combustible fraction of Municipal Solid Waste (MSW) and industrial waste using different converting techniques. ${ }^{4}$ SRF is a type of standardised RDF within the framework of the European Committee for Standardization Technical Committee 343 (CEN/TC 343). 5 The inconveniences related to the uncertainties of the properties of RDF are improved in the case of SRF. However, in this study (as the samples are directly received from the cement plants and the authors are not certain whether they are RDF or SRF) both RDF and SRF are denoted as RDF. RDF is a highly heterogeneous fuel composed of different materials such as paper, cardboard, wood, plastics, inerts, etc. ${ }^{6}$ The composition of RDF depends on the supplier, the sorting and separation process, the source material it is produced from, and the time of the year that it has been produced. ${ }^{7}$ As each of the material

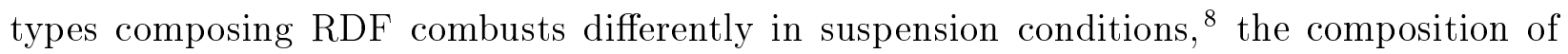
RDF affects the combustion and the temperature distribution in the cement calciner and the rotary kiln. The effect of RDF co-firing on the performance and operating conditions of calciners and rotary kilns is investigated in some of the previous studies. ${ }^{9-12}$ Apart from the cement industry, RDF combustion or co-firing is widely used in other industrial reactors and furnaces, e.g., power plant boilers and fluidized beds. $\stackrel{13-15}{-15}$ However, in the present study, RDFs utilized in the cement industry are studied.

In a cement plant, the raw meal particles, which are mainly composed of calcium carbonate, are initially heated by passing through a series of cyclones and afterwards, go through calcination (in suspension condition) and clinker reactions (in a bed of material), respec- 
tively, in the cement calciner and rotary kiln. As the calcination and clinker reactions are endothermic, it is common that suspension firing of solid-fuel particles is utilized in the calciner and rotary kiln. $\frac{16}{2}$ RF particles used in the cement industry are usually larger in size and highly scattered in shape compared to traditional pulverized fossil fuels. The effect of size and shape of single biomass $\frac{1718}{18}$ and plastic $\frac{19}{19}$ particles on the combustion time is studied in the literature. It takes a longer time for larger-sized RDF particles to combust in the calciner and the rotary kiln compared to the conventional pulverised fossil fuels. Accordingly, one of the main challenges in utilization of RDFs in the cement industry is the fuel burnout degree. In rotary kiln, the unburnt fuel would end up on the material charge and may result in reduced cement quality. ${ }^{[20}$ In cement calciner, the unburnt fuel particles will be carried out along with the calcined raw meal to the lowest cyclone and may cause melt-induced buildups. ${ }^{16}$ In order to reduce or remove the mentioned effects, a limited size of RDF particles should be used for combustion in cement plants. For example, it is suggested that the $90^{\text {th }}$ percentile grain size (using mechanical sieving) of RDF particles used in the cement calciner and rotary kiln should be smaller than $80 \mathrm{~mm}$ and $30 \mathrm{~mm}$, respectively. ${ }^{2122}$

Besides the long conversion time of RDF particles, another parameter that affects the RDF burnout degree in the cement calciner or the rotary kiln is the residence time of particles in suspension before they exit the calciner or drop on the charge in the rotary kiln. The residence time of non-spherical RDF particles is governed by their aerodynamic behaviour in suspension condition. The aerodynamic behaviour of non-spherical particles is extensively studied in the literature and the most important parameters affecting this behaviour are the particle size, shape, and density. $\underline{23}[29$

For the case of non-spherical RDF particles, the shape of fuel particles is very complex and scattered which makes the determination of particle size and shape a challenging task (examples of particle shapes are provided in Appendix A). There have been a limited number of studies in the literature regarding the determination of size and shape of RDF particles 
combined with their aerodynamic properties. Krueger et al. ${ }^{30}$ used a camera setup to determine the volume and sphericity of some prototype as well as RDF particles; afterwards they tested the individual particles in a vertical free-fall channel to monitor and record the instantaneous drag coefficient applied to the particles from the still air. They showed that for the prototype non-spherical particles, a fluctuation in the terminal velocity of particles were observed due to the secondary particle movements, e.g. tumbling and rotary motion. Also they reported that the existing models in literature were not able to predict the drag coefficient properly, especially for particles with low sphericity. Dunnu et al. ${ }^{3132}$ used a wind sieve setup in combination with particle imaging. They proposed a new and constant drag coefficient of 1.5 for particles with terminal velocities in the Newton's region. However, they did not measure the mass of individual particles, but estimated it using the projected area diameter, i.e. diameter of a sphere having the same projected area as that of the particle, and an assumed density. This method imposes some uncertainties in determination of the particle mass.

The literature survey reveals that there is no extensive study connecting the size, shape, and mass of the RDF particles to their aerodynamic behaviour. The present study aims to improve the quantitative basis of RDF physical characterization with an emphasis on input parameters needed for CFD modelling of RDF combustion in suspension, i.e., correct size and shape distribution as well as appropriate drag model. A method for aerodynamic characterization of RDF samples using a wind sieve setup is presented. Two of the samples are chosen for further physical analysis, i.e., mass measurement and 2D photographing. A new approach to calculate terminal velocity based on the mass and maximum projected area of particles is proposed. The results from the proposed method are compared with results obtained using the drag models in the literature. Finally, a reverse method is provided to estimate the mass distribution of particles of each group from the wind sieve data. 


\section{Experimental}

Six RDF fuel samples produced by different suppliers are received from three cement plants. Details about the RDF samples are summarized in Table 1. Except RDF-C which is composed of homogeneous granular tire, the RDF samples are generally constituted of heterogeneous shredded materials such as plastic, paper, cardboard, wood, etc. The original fuel samples are sterilized and dried in an oven with a maximum temperature of $105^{\circ} \mathrm{C}$. Afterwards they are divided into representative samples using the quartering method (see section 2.2. . The fuels have been subjected to a number of tests which will be described in this section.

\subsection{Fuel separation: wind sieve}

A schematic representation of the wind sieve setup is presented in Fig. 1. This setup is composed of a vertical transparent tube with an internal diameter of $24.4 \mathrm{~cm}$ and a height of $333 \mathrm{~cm}$. The wind sieve is connected to the ventilation system and the air bulk velocity in the wind sieve is controlled by a standard Pitot tube placed close to the exit of the wind sieve and across the diameter of the cross-section. A manual enclosed feeder is placed at nearly the middle of the tube which enables an operator to feed the RDF particles to the system. Approximately $20 \mathrm{~cm}$ upstream of the particle feed, a $2 \mathrm{~cm}$ diameter hole is devised to measure the air flow velocity along the diameter of the wind sieve using a TESTO 400 anemometer. During the operation of the wind sieve, this hole is closed. Two cyclones are placed downstream of the wind sieve tube for collection of particles carried up by the air flow.

Once the particles enter the wind sieve tube, they are separated into two groups of light and heavy fractions, gathered from the top (after the cyclone) and the bottom of the wind sieve, respectively. For each sample, the wind sieve experiments are carried out for several 
velocity set-points. The starting experiment is done with the lowest velocity set-point. The heavy fraction from this experiment is used for the next experiment with a higher velocity set-point. This procedure is continued until the highest velocity set-point and the initial fuel sample will be divided into different groups; each group of particles has a specific terminal velocity range. The number of groups that the particles are categorised into is one more than the number of velocity set-points. The size of RDF particles remain unchanged during and after the wind sieve experiment. For the current detailed study, i.e., wind sieve and particle imaging, the velocity set-points of $2,3,5$, and $7 \mathrm{~m} / \mathrm{s}$ are used; so the initial fuel sample is divided into particle groups with terminal velocity ranges of $<2,2-3,3-5,5-7$, and $>7$ $m / s$. For some of the fuel samples, the experiments are repeated for different representative samples of that fuel to test the repeatability of the experiments.

During the operation of the wind sieve, the actual temporal velocity inside the wind sieve oscillates to some extent around the set-point velocity. The actual velocity is monitored during the experiments and the feeding of particles is stopped when this velocity increases or decreases $0.5 \mathrm{~m} / \mathrm{s}$ from the set-point value. Higher fluctuations in the velocity are observed for smaller set-point velocities, i.e. 2 and $3 \mathrm{~m} / \mathrm{s}$.

During the experiments, small samples of particles (less than 20 particles in each sample) are fed manually to the wind sieve with a high speed; so that they hit the front wall and deagglomerate. In this way, the possibility of particle agglomeration and subsequent increase in the terminal velocity of agglomerated particles is reduced. The procedure of feeding is carried out with a slow pace, i.e. each feeding is done after all of the particles from the previous feeding have left the wind sieve, so that the change in the air velocity inside the wind sieve due to the presence of particles is negligible. 


\subsection{Fuel separation: manual}

Pyrolysis of the lignocellulosic (biomass) and plastic fractions in RDF takes place at different temperature ranges. ${ }^{33}[36$ TGA curves from RDF pyrolysis are mainly composed of two distinct peaks with approximate temperature ranges of $250-400^{\circ} \mathrm{C}$ and $450-500^{\circ} \mathrm{C}$ corresponding to the main fractions of lignocellulosic and plastic materials, respectively. ${ }^{33}$ As plastic and biomass fractions in RDF have different pyrolysis behaviours, in the current study, the fuel sample is manually separated into two main sub-fractions of biomass (wood, paper, and cardboard) and plastics (2D and 3D). Furthermore, the minor sub-fractions are fine (smaller than $2 \mathrm{~mm}$ ), inert, and textile.

If the separated sample from the wind sieve experiment contains a large amount of particles, quartering of the sample is carried out to reduce it to a smaller representative sample size. ${ }^{[37}$ In the quartering procedure, the sample is piled up on a plate or canvas and is divided into four parts using a rod. Then the opposite parts are added together and the sample is reduced to two representative parts. The quartering might be repeated if the representative sample is still large. However, it should be noted that quantification of the representativeness of reduced samples is difficult and time-consuming. But it is expected that the samples from the widely applied quartering method,, 37 are representative.

The representative sample that is reduced in size is sieved using a mechanical sieve to separate the fine particles, i.e., particles smaller than $2 \mathrm{~mm}$. The rest of the sample is classified visually into four fractions of plastics, biomass, textile and inert based on the particle texture. Particles from the fine fraction of the sample are too small to perform a manual separation. This procedure is repeated for all of the separated groups of particles from the wind sieve. Once the material-based separation of the representative sample is completed, each individual particle from the biomass and plastic fractions is characterized by weight measurement as well as $2 \mathrm{D}$ imaging. 


\section{$2.32 \mathrm{D}$ imaging}

A photographing platform shown in Fig. 2 is used to take two pictures of individual particles from two different angles, i.e. top and side pictures. The cameras are calibrated with three objects of pre-defined areas. For each individual particle, the weight of the particle is measured using a scale with an accuracy of $0.01 \mathrm{mg}$. Afterwards, the individual particles are rested on the photographing platform before taking $2 \mathrm{D}$ pictures from top and side of the particle. For the side picture, it has been tried to orient the particle in a way that the projected area from the side picture would become maximum. The particle projected areas in two directions are estimated from the $2 \mathrm{D}$ images. The final maximum projected area is the larger value between the projected areas from the top and side images. The number of representative particles tested for each wind sieve group (biomass or plastic) is typically in the range of $100-200$.

\section{Aerodynamics of non-spherical particles}

\subsection{Particle drag force}

When the particle to gas density ratio is significantly higher than unity, the drag force applied on a single particle by the carrier gas can be formulated as below,

$$
\overrightarrow{F_{D}}=\frac{1}{2} C_{D}\left(A_{p}\right)_{\perp} \rho_{g}\left|\overrightarrow{U_{g}}-\overrightarrow{U_{p}}\right|\left(\overrightarrow{U_{g}}-\overrightarrow{U_{p}}\right)
$$

with $\overrightarrow{U_{g}}$ and $\overrightarrow{U_{p}}$ being the gas velocity vector at the particle position and the particle velocity vector, respectively. $\left(A_{p}\right)_{\perp}$ is the projected area of the particle normal to the direction of relative velocity between the gas and the particle and $\rho_{g}$ is the gas density. The drag coefficient, $C_{D}$, depends on the particle shape and the particle Reynolds number, $R e_{p}=$

$\rho_{g} d_{p} \frac{\left|\overrightarrow{U_{f}}-\overrightarrow{U_{p}}\right|}{\mu_{f}}$, where $d_{p}$ is the particle diameter and $\rho_{g}$ and $\mu_{g}$ are the gas density and viscosity, 
respectively.

For spherical particles with Re numbers below 1000, the drag model proposed by Schiller

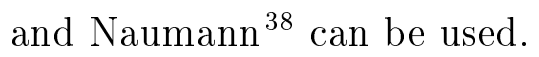

$$
C_{D}=\frac{24}{R e_{p}}\left(1+0.15 R e_{p}^{0.687}\right) \quad R e_{p}<1000
$$

At higher Reynolds number values, $R e_{p}>1000$, the flow around spherical particles becomes turbulent and usually a constant drag coefficient of $C_{D}=0.44-0.46$ is used. $\frac{3839}{38}$ For particles with very high Reynolds numbers, e.g. around $2 \times 10^{5}$ and higher, there is a boundary layer separation on the particle surface and the drag coefficient is significantly reduced. $\stackrel{40}{ }$

For a particle in terminal condition, i.e. the drag force applied to the particle equals to the particle gravitational force, the drag force equation (1) can be simplified to the following form,

$$
\frac{\left(A_{p}\right)_{\perp}}{m_{p}}=\frac{2 g f_{w}^{2}}{C_{D} \rho_{g} V_{t}^{2}}
$$

with $m_{p}, g$, and $V_{t}$ being the particle mass, gravitational acceleration, and the particle terminal velocity, respectively. $f_{w}=1-\left(\frac{\left(A_{p}\right)_{\perp}}{\pi D_{t}^{2} / 4}\right)^{0.75}$ is a wall correction factor that is previously used by Dunnu et al. ${ }^{31}$ to account for the effect of wind sieve tube diameter in comparison to the particle diameter. This correction formula is valid for $\frac{d_{p}}{D_{t}} \leqslant 0.8$ and $R e_{p} \leqslant 10^{4}$ which is satisfied for most of the tested particles.

For non-spherical particles, besides the particle size, the shape of the particle also influences the drag force applied to the particle from the gas. There are different ways to parametrize the size and shape of non-spherical particles. Among the existing literature models for the drag coefficient of non-spherical particles, the equivalent-volume diameter (shown as $d_{p}$ in this study), i.e. diameter of a sphere having the same volume as that of the particle, ${ }^{41}$ and the degree of true sphericity, ${ }^{42}$ i.e. the ratio of external surface area 
of volume-equivalent sphere to the actual surface area of the particle, $\phi_{p}$, are used more frequently. Some of the well-known correlations for the drag coefficient of non-spherical particles that have used the mentioned size and shape characterizations are summarised in Table 2. Furthermore, it is worthy to mention that for exact and instantaneous aerodynamic characterization of non-spherical particles, the lift coefficient also needs to be taken into account. The lift coefficient is not investigated in this study.

\subsection{Mass-based particle size distribution}

In general, when a continuous size distribution is assumed for a material, two parameters are defined; one quantifies the average size of particles, and the other one describes the spread of the distribution over the average value. This method is acceptable when the shape of the particle size distribution curve is similar for all cases; however, for the case of waste derived fuels, this condition is not satisfied. $\frac{43}{4}$ One of the methods that has been proven to give a proper fit for the size distribution of particles from waste derived fuels ${ }^{44}$ is the Rosin-Rammler distribution. The Rosin-Rammler distribution is originally and widely used

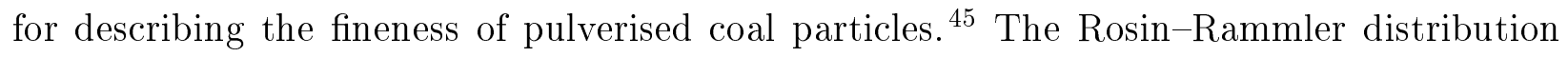
based on the mass of particles can be written in percentage as, $\underline{46}$

$$
Y=100\left[1-\exp \left(-\frac{d}{d_{m}}\right)^{n}\right]
$$

where $d_{m}$ is the $63^{r d}$ percentile of particle mass and $n$ is the spreading parameter.

\subsection{Particle shape}

In order to estimate the particle volume, $V_{p}$, from the particle mass, $m_{p}$, constant densities of 950 and $650 \mathrm{~kg} / \mathrm{m}^{3}$ are assumed for the plastic and biomass particles, respectively. The selected values are close to the ones used by. ${ }^{8}$ Then the volume of the particle is calculated 
from the following relation,

$$
V_{p}=\frac{m_{p}}{\rho_{p}}
$$

where $\rho_{p}$ is the particle density. By assuming that the particles are cuboids, the thickness of each individual particle, $t_{p}$, is calculated from the following relation.

$$
t_{p}=\frac{V_{p}}{A_{p}}
$$

where $A_{p}$ is the particle maximum projected area from $2 \mathrm{D}$ imaging. Only the information

from one of the images is used for calculation of particle thickness. Using Eqs. (5) and (6), and assuming particles are cuboids, it is possible to simplify the particle sphericity equation to the below relation,

$$
\phi_{p}=\frac{\pi\left(6 V_{p} / \pi\right)^{2 / 3}}{2 A_{p}+4 t_{p} A_{p}^{1 / 2}}
$$

This equation is used in subsequent sections of this study for calculation of particle sphericity.

An experimental flowchart summarizing the process of sample preparation, experimental methods and tests, and drag model studies and development is presented in Fig. 3 .

\section{Results and discussions}

\subsection{Wind sieve}

\subsubsection{Wind sieve velocity distribution}

For fuel samples RDF-A and $\mathrm{RDF}-\mathrm{B}$, the wind sieve experiments are carried out with velocity set-points of $2,3,5$, and $7 \mathrm{~m} / \mathrm{s}$. For the mentioned velocity set-points, point measurements of velocity upstream of the particle feed and along a diameter of the wind sieve tube are carried out over a period of 60 seconds. Each point measurement is repeated 
three times. The measured air flow velocity distribution is presented in Fig. 4 for the chosen velocity set-points. It can be observed that the velocity magnitude is biased to some extent toward $r / R=-1$ side which can be attributed to a small swirl inside the wind sieve. In general, as the gas velocity is lower in regions close to the walls, the center velocity is slightly higher than the set-point value. For the measured velocities in the wind sieve, the maximum relative deviation from the set-point velocity corresponds to the nearest measurement point close to the wall and in the range of $13-24 \%$.

\subsubsection{Wind sieve overall results}

In general, RDF-particles used in the cement calciners can have a lower quality, e.g. larger size, higher moisture content, and lower heating value, than the ones used in the rotary kiln. ${ }^{21}$ In this section, a comparison of the wind sieve results of different RDF samples with respect to fuel physical and material properties (if available) as well as the place of use is given. Depicted in Fig. 5 are the overall results of the wind sieve experiments for RDF samples presented in Table 1. $\mathrm{RDF}-\mathrm{C}$ is constituted of the smallest particle size among other tested fuels. The fuel particles are crushed to a size smaller than $3 \mathrm{~mm}$. Even though this fuel can be used both in calciner and rotary kiln, its relatively high heating value and high cost makes it more suitable to be used in the rotary kiln where a higher quality fuel is needed compared to the calciner. The wind sieve results of the samples RDF-A, RDF-B, and $\mathrm{RDF}-\mathrm{D}$ lie in the middle part of the plot. These fuel samples are mainly used in the calciner except $\mathrm{RDF}-\mathrm{B}$, which is used in the rotary kiln as well. RDF-D is slightly lighter than the other two samples. Fuels RDF-E and RDF-F are the heaviest samples tested in the wind sieve. Overall, these fuels constitute particles larger than the particles present in the rest of fuel samples which makes them more difficult-to-burn. RDF-F is used in

the HOTDISK ${ }^{\circledR}$ which is an extension to the calciner to provide enough residence time for difficult-to-burn fuel particles to burn out properly. $\underline{47}$ 


\subsection{Material properties}

\subsubsection{Manual separation}

RDF-A and RDF-B are further analysed for physical and material characterization. Exam-

ples of RDF-A particles from the manual separation and for each terminal velocity range is provided in Appendix A. For plastics, the particles belonging to the low terminal velocity ranges of the wind sieve, i.e. lower than $3 \mathrm{~m} / \mathrm{s}$, are soft and flexible and have a $2 \mathrm{D}$ shape, e.g. plastic foils. The plastic particles with a higher terminal velocity are more rigid, thick and with different complex 3D shapes, e.g., cylindrical. The same criteria is also valid for biomass particles. The biomass particles of the low terminal velocity groups, i.e. lower than $3 \mathrm{~m} / \mathrm{s}$, are mainly paper and as the terminal velocity increases, cardboard and wood particles can also be found in the separated wind sieve particle group. The low terminal velocity textile particles are mainly strings and light fluffy materials such as pieces of napkins. These particles are usually responsible for agglomeration of light particles. As the terminal velocity increases, the textile particles become heavier and 3D. The fine particles (smaller than 2 $\mathrm{mm}$ ) look nearly the same for all of the wind sieve groups and are composed of both combustible and non-combustible materials. It is likely that during the wind sieve, the manual separation, and the mechanical shaking sieve experiments, some of the fine particles would separate from the bigger particles. As a result, they may belong to a terminal velocity range that is higher than their actual terminal velocity. The fine particles with a terminal velocity higher than $7 \mathrm{~m} / \mathrm{s}$ are mainly non-combustibles such as small stones and glass particles. The inert particles are mainly pieces of glass, stone, and metal with different sizes.

A comparison of the composition of $\mathrm{RDF}-\mathrm{A}$ and $\mathrm{RDF}-\mathrm{B}$ samples for each wind sieve velocity range after the manual separation is provided in Fig. 6. It can be observed that even though the RDF samples have approximately the same overall mass distribution from the wind sieve experiment, the material-based distributions are different. For both of the 
RDF samples and for low terminal velocity ranges, i.e. below $3 \mathrm{~m} / \mathrm{s}$, the plastic fraction is high; but the plastic fraction in $\mathrm{RDF}-\mathrm{A}$ is approximately twice of that of the RDF-B. On the other hand, the fine fraction is high for RDF-B. For higher terminal velocity ranges, i.e. above $3 \mathrm{~m} / \mathrm{s}$, the biomass fraction is the dominant fraction and the amount of biomass fraction in $\mathrm{RDF}-\mathrm{A}$ is higher than $\mathrm{RDF}-\mathrm{B}$. It is worthy to mention again that the $\mathrm{RDF}-\mathrm{A}$ and $\mathrm{RDF}-\mathrm{B}$ were produced by two different suppliers; so it is expected that their material composition would be different.

\subsection{Physical properties}

The process of 2D imaging and mass measurement of individual particles is carried out for $\mathrm{RDF}-\mathrm{A}$ and $\mathrm{RDF}-\mathrm{B}$ samples. In this section, the physical and aerodynamic properties of the tested RDF particles in combination with the information from the wind sieve experiments are discussed.

\subsubsection{Mass distributions}

The Rosin-Rammler mass distributions of the tested RDF samples are plotted in Fig. 7. The values of $d_{m}$ and $n$ from the Rosin-Rammler fitted distributions are summarized in Table 3 for each particle group from the wind sieve. As expected, the average value of mass, $d_{m}$, increases for particle groups of higher terminal velocity. However, for the plastic or biomass particles belonging to a specific terminal velocity range, no particular trend or range can be seen in the average mass values or the mass distributions. The range of mass distribution of plastic or biomass particles may change by an order of magnitude for a terminal velocity range. The particles from $\mathrm{RDF}-\mathrm{A}$ sample are generally heavier than $\mathrm{RDF}-\mathrm{B}$. In contrast, the spread parameters lie in the range of 1.35-1.92 for all of the tested groups of particles. 


\subsubsection{Shape distributions}

Presented in Figs. 8 and 9 are the scatter distributions of the maximum projected area of particles versus mass for biomass and plastic fractions of RDF-A and RDF-B. Linear trend lines are fitted to the scatter plots and the slope of the lines is weighted with the mass of particles and summarized in Table 4. For each terminal velocity range and for both fuel samples, regardless of the particle material type, the slope of the fitted trend lines (the ratio of particle maximum projected area to the particle mass) lie in a specific range.

The free falling behaviour of non-spherical particles is investigated in literature. For low Reynolds numbers, i.e. below 100, non-spherical particles fall in a steady (or a damped oscillating) motion with their maximum projected area perpendicular to the direction of falling. ${ }^{48-50}$ For higher Reynolds numbers, particles may exhibit complicated motion patterns during falling such as oscillations, glide-tumbling, or tumbling. ${ }^{48}$ It can be stated that for these Reynolds numbers, on average, the particles may fall with an area smaller than the maximum projected area. In the present study, for most of the particles in terminal condition, the Reynolds number of particles (based on volume-equivalent diameter) is higher than 100 and for some particles, it lies in the turbulent region, i.e. particle Reynolds number larger than 1000, where the drag coefficient becomes constant. The behaviour observed in Figs. 8 and 9 can be explained by stating that at the free falling conditions, the maximum projected area of non-spherical particles still plays an important role in the drag force applied to them. Considering the right hand side of Eq. (3), it can be stated that the ratio of maximum projected area of a non-spherical particle in terminal condition to its mass is a function of terminal velocity and the drag coefficient. For each group of particles from the wind sieve, the terminal velocity lies in a narrow range. This indicates that the drag coefficient for all of the particles in a terminal velocity range should also lie in a limited range so that the left hand side of Eq. (3) stays nearly constant. Further discussion about this equation will be 
given in section 4.4 .

The sphericity of the tested particles is estimated using Eq. (7) and presented as scatter distributions in Fig. 10. The mass-weighted averages of the particle sphericities are summarized in Table 5. It can be stated that for all wind sieve groups except the heaviest fraction, the biomass sphericity is higher than the plastic one, indicating that the plastic particles are flatter on an average basis. This is in agreement with the visual observations of particles during the measurements as well as the fact that the dominant RDF particles in the smallest velocity range, i.e. $<2 \mathrm{~m} / \mathrm{s}$, are made of plastics (the flatter the particles are, the lower the terminal velocity). For the heaviest group of particles, the sphericity is in the same range for biomass and plastic particles.

The average sphericity of RDF-A particles is slightly smaller than RDF-B particles. This can be attributed to the higher average mass of RDF-A particles (based on Table 3) that indicates the particles should be flatter to have the same terminal velocity range as the particles with a smaller mass. For particle groups with a terminal velocity higher than $5 \mathrm{~m} / \mathrm{s}$, a weak tendency of a reduction in the particle sphericity for heavier particles is observed. A similar reasoning can also be given here. The heavier particles belonging to a wind sieve group should have a larger projected area compared to the lighter particles; so that both heavy and light particles lie in the same terminal velocity range.

\subsection{Aerodynamic properties}

According to the discussion given in section 4.3.2, it is suggested to calculate the terminal velocity of RDF particles tested in the wind sieve by rearranging Eq. (3) and assuming that the particles fall with their maximum projected area perpendicular to the direction of falling even though, as explained before, this assumption may not be completely correct. In this way, $\left(A_{p}\right)_{\perp}$ is equivalent to the maximum projected area. The rearranged equation can be 
written as below,

$$
V_{t}=\sqrt{\frac{2 g m_{p} f_{w}^{2}}{\left(A_{p}\right)_{\perp} C_{D} \rho_{g}}}
$$

The particle Re number is calculated according to the volume-equivalent diameter of the particle. Dunnu et al. $\frac{31}{3}$ have proposed a similar method. However, they have suggested a new and constant drag coefficient for all of the particles. In the current study though, the drag coefficient is calculated by assuming that the particles are spherical (see section 3.1). Most of the large particles tested in the wind sieve lie in the turbulent region of the drag coefficient plot if they are considered spherical (volume-equivalent). So the drag coefficient for most of the particles is equal to 0.44 .

The predicted terminal velocity of RDF particles from the wind sieve using the proposed method is presented in Fig. 11. In this figure, the velocity range of each wind sieve group is depicted as two straight lines. For most of the RDF particles in each wind sieve group especially the heavier particles, the predicted terminal velocity lies within the wind sieve velocity range. The terminal velocity of some of the lighter particles from the $2-3,3-5$, and 5-7 m/s wind sieve groups is under-predicted, though. To the authors' knowledge, this can be attributed to several behaviours. There is a higher tendency for the lighter particles to agglomerate in the wind sieve, especially if they are close to texture-made particles (strings and fluffy particles). The agglomerated group of particles would have a higher terminal velocity than the individual particles. Furthermore, as the gas velocity close to the walls is smaller than the center velocity, there might be a tendency for smaller particles to accumulate near the walls and then fall down. However, we are not sure if this behaviour happened during the experiments. Finally, some deviation in the magnitude of estimated terminal velocity can be caused by the uncertainty of the proposed drag model. Even though the model works well for the heavy particles, the aerodynamics of the smaller particles in the wind sieve might be different. 
Even though the agreement in estimation of the terminal velocity of particles using the proposed model is acceptable, in the literature studies, the constant drag coefficient of nonspherical particles lying in the turbulent regime is commonly higher than the value of 0.44 for spherical particles. ${ }^{[29}$ Furthermore, as stated before, most of the studied particles fall with a Reynolds number higher than 100; indicating that they fall with an area smaller than their maximum projected area. The multiplication of maximum projected area and $C_{D}$ of spherical particles in Eq. (8) may result in the same drag force applied to the particle compared to a case where the real falling area is multiplied to the $C_{D}$ of non-spherical particles. The systematic underestimation of terminal velocity of particles with small mass may also arise from this effect which needs further investigation.

Similar to the proposed model, the terminal velocity of the tested RDF particles is predicted by the well-known existing drag models presented in Table 2 . For the literature drag models (if relevant), it is assumed that the projected area of the particle normal to the direction of relative velocity, $\left(A_{p}\right)_{\perp}$, is equivalent to the particle maximum projected area; and the average projected area of the particle parallel to the direction of the relative velocity, $\left(A_{p}\right)_{\|}$, is equivalent to the projected area of the particle from the side picture. The mass-weighted average of the predicted terminal velocity for each wind sieve group and for different drag models is summarized in Table 6. For most of the tested particles, the particle sphericity value is sufficiently low to be either outside of the validity range or in the lowaccuracy range of the drag model. For almost all of the existing literature drag models, the terminal velocity is under-predicted indicating that the drag force applied to the particles is over-predicted. The best average values are obtained from the current model. Among the literature models, the Hölzer and Sommerfeld ${ }^{29}$ drag model predicts the terminal velocity of particles better than the other drag models.

It should be mentioned that for CFD simulations of reactive systems operating with RDF, as plastic particles in RDF go through a shape change (after melting), the proposed drag 
suggestion might need an extension to account for the change in shape of plastic particles.

\subsection{Estimation of mass distributions}

Similar to the method provided in section 4.4, the mass of individual particles can be estimated by rearranging Eq. (8) as below,

$$
m_{p}=\frac{V_{t}^{2}\left(A_{p}\right)_{\perp} C_{D} \rho_{g}}{2 g f_{w}^{2}}
$$

while having the knowledge about the maximum projected area as well as the terminal velocity range of particles. It is assumed that for the particles belonging to the terminal velocity ranges of $<2,2-3,3-5,5-7$, and $>7 \mathrm{~m} / \mathrm{s}$, the mid-point terminal velocity would be equal to $1.75,2.5,4,6$, and $8.6 \mathrm{~m} / \mathrm{s}$ (the values of 1.75 and $8.6 \mathrm{~m} / \mathrm{s}$ are chosen using a reverse algorithm based on Table 4 and Eq. (8)). Along the actual mass distribution of particles, the estimated cumulative mass of particles is depicted in Fig. 7. For particles with an actual mass below $10 \mathrm{mg}$, the estimated mass is over-predicted for most of the particle groups from the wind sieve. A similar reasoning provided in section 4.4 for the light particles of each wind sieve group can also be given here. For the particles belonging to the terminal velocity group of $<2 \mathrm{~m} / \mathrm{s}$, the assumption of average terminal velocity of $1.75 \mathrm{~m} / \mathrm{s}$ may not be appropriate for very small particles.

The estimated Rosin-Rammler distributions from the mentioned method as well as the average relative error compared to the values presented in Table 3 are summarized in Table 7. The maximum average error is for the particles belonging to the terminal velocity group of $<2 \mathrm{~m} / \mathrm{s}$. For the rest of particle groups from the wind sieve, the average errors are below $20 \%$. The proposed method for estimation of RDF particles mass while having the knowledge of particles maximum projected area, based on 2D imaging, as well as the mid-point terminal velocity, based on the wind sieve experiment information, can be used as a simplification of 
the procedure required for determination of size, shape, and mass of particles. This procedure can be summarized as below,

1. Particles belonging to a wind sieve group are distributed on a plate suitable for $2 \mathrm{D}$ imaging. The particles should be scattered on the plate with no touching of boundaries. A picture is taken from the whole group of particles.

2. The picture is post processed to estimate the maximum projected area of individual particles.

3. The mass of particles is calculated based on Eq. (9) and by assuming mid-point terminal velocities of $1.75,2.5,4,6$, and $8.6 \mathrm{~m} / \mathrm{s}$ for the terminal velocity ranges of $<2,2-3,3-5,5-7$, and $>7 \mathrm{~m} / \mathrm{s}$.

4. Once the mass of individual particles is estimated, the sphericity can be calculated based on Eqs. (5), (6), and (7).

\section{Conclusions}

Physical and aerodynamic properties of RDF particles, two important aspects affecting suspension conversion of these particles in the cement industry, are investigated in this article. The mentioned properties are characterized for a number of RDF samples using wind sieve experiments, manual separation, 2D imaging, and weight measurement of individual particles. The wind sieve is used as a tool to classify RDF particles according to their aerodynamic properties, i.e. terminal velocity range. Afterwards, for two of the RDF samples, a manual separation of the particle fractions from wind sieve experiment into fine, inert, textile, plastic, and biomass fractions are carried out. Even though the fuel samples showed similar behaviour in the wind sieve, the material type distribution of the separated groups from 
the wind sieve are significantly different. From the individual particle tests in weight measurement and 2D imaging, the mass and shape distribution of particles are characterized. According to the distribution of particle mass versus particle maximum projected area, a new approach is proposed to predict terminal velocity of non-spherical RDF particles from the wind sieve. The proposed method provides an accurate prediction of the terminal velocity of particles with the highest average deviation (from the mid-point velocity) below $14 \%$. Finally, new method is proposed to physically characterize RDF based on wind sieve and 2D imaging, and then use Eq. (9) to calculate mass distribution. The obtained properties can be applied as an input in CFD simulations of cement calciners and rotary kilns operating with RDF.

\section{Acknowledgement}

This study was supported within the advanced technology platform "Minerals and Cement Process Technology - MiCeTech" funded by the Innovation Fund Denmark, FLSmidth A/S, Hempel and the Technical University of Denmark (Grant No. 39-2013-2). The authors would like to thank FLSmidth R\&D Center Dania, Mariager, Denmark, for providing sample preparation and performing some of the wind sieve tests as well as Imran Khan and Casper Stryhn Svith for performing some of the wind sieve tests.

\section{A RDF samples after manual separation}

In this appendix, examples of RDF-A particles after manual separation are provided in Figs. 12 to 16 . The description of each of the particle materials is given in section 4.2.1. 


\section{References}

(1) Sarc, R.; Lorber, K.; Pomberger, R.; Rogetzer, M.; Sipple, E. Design, quality, and quality assurance of solid recovered fuels for the substitution of fossil feedstock in the cement industry. Waste Management and Research 2014, 32, 565-585, DOI: $10.1177 / 0734242 \times 14536462$.

(2) Aranda Usón, A.; López-Sabirón, A.; Ferreira, G.; Llera Sastresa, E. Uses of alternative fuels and raw materials in the cement industry as sustainable waste management options. Renewable and Sustainable Energy Reviews 2013, 23, 242-260, DOI: $10.1016 / j . r s e r .2013 .02 .024$.

(3) Ariyaratne, W.; Melaaen, M.; Tokheim, L. Determination of biomass fraction for partly renewable solid fuels. Energy 2014, 0, 465-472, DOI: $10.1016 / j$.energy .2014.04.017.

(4) Diaz, L.; Savage, G.; Eggerth, L.; Rosenberg, L. Solid Waste Management; UNEP International Environmental Technology Centre, United Nations Environment Programme, 2005; Vol. 1.

(5) CEN (European Committee for Standardization), CEN/TC 343 - Solid Recovered Fuels, Brussels, Belgium. 2012.

(6) Krüger, B.; Mrotzek, A.; Wirtz, S. Separation of harmful impurities from refuse derived fuels (RDF) by a fluidized bed. Waste Management 2014, 34, 390-401, DOI: $10.1016 /$ j.wasman .2013 .10 .021$.

(7) Leavens, A.; Hogg, D.; del Buffalo, N.; Giegrich, J.; Fehrenbach, H.; Gromke, U.; Gendebien, A.; Blackmore, K.; Godley, A.; Lewin, K. 
Refuse Derived Fuel, Current Practice and Perspectives, B4-3040/2000/306517/MAR/E3; European Commission - Directorate General Environment, 2003.

(8) Liedmann, B.; Arnold, W.; Krüger, B.; Becker, A.; Krusch, S.; Wirtz, S.; Scherer, V. An approach to model the thermal conversion and flight behaviour of Refuse Derived Fuel. Fuel 2017, 200, 252-271, DOI: 10.1016/j.fuel.2017.03.069.

(9) Bluhm-Drenhaus, T.; Wirtz, S.; Scherer, V.; Perumalsamy, S.; Oeljeklaus Habil, G.; Görner, K.; Asian, Z.; Schäfer, S.; Hoenig, V. CFD simulation of the co-incineration of solid recovered fuels in the precalciner. Cement International 2011, 9, 54-63.

(10) Liedmann, B.; Wirtz, S.; Scherer, V.; Krüger, B. Numerical Study on the Influence of Operational Settings on Refuse Derived Fuel Co-firing in Cement Rotary Kilns. Energy Procedia 2017, 120, 254-261, DOI: 10.1016/j .egypro.2017.07.176.

(11) Haas, J.; Weber, R. Co-firing of refuse derived fuels with coals in cement kilns: Combustion conditions for stable sintering. Journal of the Energy Institute 2010, 83, 225-234, DOI: $10.1179 / 014426010 X 12839334040898$.

(12) Ariyaratne, W. K.; Melaaen, C. M.; Tokheim, L. A. Optimum feeding rate of solid hazardous waste in a cement kiln burner. International Journal of Energy, Environment and Economics 2013, 4, 777-786.

(13) Wu, H.; Pedersen, A.; Glarborg, P.; Frandsen, F.; Dam-Johansen, K.; Sander, B. Formation of fine particles in co-combustion of coal and solid recovered fuel in a pulverized coal-fired power station. Proceedings of the Combustion Institute 2011, 33, 2845-2852, DOI: $10.1016 / j \cdot p r o c i .2010 .06 .125$.

(14) Manninen, H.; Peltola, K.; Ruuskanen, J. Co-combustion of refuse-derived and packaging-derived fuels (RDF and PDF) with conventional fuels. Waste Management and Research 1997, 15, 137-147, DOI: 10.1006/wmre.1996.0072. 
(15) Maier, J.; Gerhardt, A.; Dunnu, G. Experiences on Co-firing Solid Recovered Fuels in the Coal Power Sector. Green Energy and Technology 2011, 28, 75-94.

(16) Larsen, M. B. Alternative Fuels in Cement Production. Ph.D. thesis, Technical University of Denmark, Department of Chemical and Biochemical Engineering, 2007.

(17) Momeni, M.; Yin, C.; Kær, S.; Hansen, T.; Jensen, P.; Glarborg, P. Experimental study on effects of particle shape and operating conditions on combustion characteristics of single biomass particles. Energy and Fuels 2013, 27, 507-514, DOI: $10.1021 /$ ef 301343q.

(18) Mason, P.; Darvell, L.; Jones, J.; Pourkashanian, M.; Williams, A. Single particle flame-combustion studies on solid biomass fuels. Fuel 2015, 151, 21-30, DOI: $10.1016 / j$. fuel.2014.11.088.

(19) Bluhm-Drenhaus, T.; Becker, A.; Wirtz, S.; Scherer, V. A model for the devolatilisation of large thermoplastic particles under co-firing conditions. Fuel 2012, 101, 161-170, DOI: $10.1016 /$ j.fuel.2012.05.041.

(20) Vaccaro, M. Burning alternative fuels in rotary cement kilns. IEEE Cement Industry Technical Conference 2006, 2006, 127-136.

(21) Lorber, K.; Sarc, R.; Aldrian, A. Design and quality assurance for solid recovered fuel. Waste Management \& Research 2012, 30, 370-380, DOI: 10.1177/0734242X12440484.

(22) Sarc, R.; Lorber, K. Production, quality and quality assurance of Refuse Derived Fuels (RDFs). Waste Management 2013, 33, 1825-1834, DOI: $10.1016 / j$. wasman .2013.05.004.

(23) Zastawny, M.; Mallouppas, G.; Zhao, F.; van Wachem, B. Derivation of drag and lift force and torque coefficients for non-spherical particles in 
flows. International Journal of Multiphase Flow 2012, 39, 227-239, DOI: 10.1016/j.ijmultiphaseflow.2011.09.004.

(24) Mandø, M.; Rosendahl, L. On the motion of non-spherical particles at high Reynolds number. Powder Technology 2010, 202, 1-13, DOI: 10.1016/j.powtec. 2010.05.001.

(25) Haider, A.; Levenspiel, O. Drag coefficient and terminal velocity of spherical and nonspherical particles. Powder Technology 1989, 58, 63-70.

(26) Ganser, G. A rational approach to drag prediction of spherical and nonspherical particles. Powder Technology 1993, 77, 143-152.

(27) Chien, S.-F. Settling velocity of irregularly shaped particles.

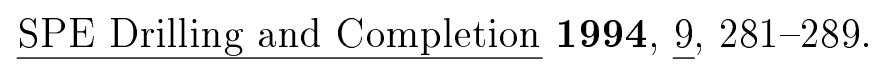

(28) Hartman, M.; Trnka, O.; Svoboda, K. Free settling of nonspherical particles. Industrial and Engineering Chemistry Research 1994, 33, 1979-1983.

(29) Holzer, A.; Sommerfeld, M. New simple correlation formula for the drag coefficient of non-spherical particles. Powder Technology 2008, 184, 361-365.

(30) Krueger, B.; Wirtz, S.; Scherer, V. Measurement of drag coefficients of non-spherical particles with a camera-based method. Powder Technology 2015, 278, 157-170, DOI: $10.1016 / j$. powtec .2015 .03 .024 .

(31) Dunnu, G.; Maier, J.; Schnell, U.; Scheffknecht, G. Drag coefficient of Solid Recovered Fuels (SRF). Fuel 2010, 89, 4053-4057, DOI: 10.1016/j.fuel.2010.06.039.

(32) Dunnu, G.; Hilber, T.; Schnell, U. Advanced size measurements and aerodynamic classification of solid recovered fuel particles. Energy and Fuels 2006, 20, 1685-1690, DOI: 10.1021/ef0600457. 
(33) Grammelis, P.; Basinas, P.; Malliopoulou, A.; Sakellaropoulos, G. Pyrolysis kinetics and combustion characteristics of waste recovered fuels. Fuel 2009, 88, 195-205, DOI: $10.1016 / j$.fuel.2008.02.002.

(34) Seo, M.; Kim, S.; Lee, S.; Lee, J. Pyrolysis characteristics of coal and RDF blends in non-isothermal and isothermal conditions. Journal of Analytical and Applied Pyrolysis 2010, 88, 160-167, DOI: 10.1016/j.jaap.2010.03.010.

(35) Bosmans, A.; De Dobbelaere, C.; Helsen, L. Pyrolysis characteristics of excavated waste material processed into refuse derived fuel. Fuel 2014, 122, 198-205, DOI: 10.1016/j.fuel.2014.01.019.

(36) Silva, R.; Martins-Dias, S.; Arnal, C.; Alzueta, M.; Costa, M. Pyrolysis and char characterization of refuse-derived fuel components. Energy and Fuels 2015, 29, 1997-2005, DOI: $10.1021 /$ ef502011f.

(37) Horwitz, W. Nomenclature for sampling in analytical chemistry (Recommendations 1990). Pure and Applied Chemistry 1990, 62, 1193-1208, DOI: 10.1351/pac199062061193.

(38) Schiller, L.; Naumann, A. Über die grundlegenden Berechnungen bei der Schwerkraftaufbereitung. Z. Ver. Dtsch. Ing 1933, 77, 318-320.

(39) Bagheri, G.; Bonadonna, C. On the drag of freely falling non-spherical particles. Powder Technology 2016, 301, 526-544, DOI: 10.1016/j . powtec. 2016.06.015.

(40) White, F. Viscous Fluid Flow; McGraw-Hill international edition; McGraw-Hill Higher Education, 2006.

(41) Yang, W.-C. Particle characterization and dynamics. Handbook of Fluidization and Fluid-particle Systems 2003, 1-28. 
(42) Wadell, H. Volume, shape, and roundness of quartz particles. Journal of Geology 1935, 43, $250-280$.

(43) Ruf, J. Particle size spectrum and compressibility of raw and shredded municipal solid waste. Ph.D. thesis, University of Florida, 1974.

(44) Savage, G.; Trezek, G. Significance of Size Reduction in Solid Waste Management; Municipal Environmental Research Laboratory, Office of Research and Development, US Environmental Protection Agency, 1980; Vol. 2.

(45) Rosin, P.; Rammler, E. Laws governing the fineness of powdered coal. Journal of the Institute of Fuel 1933, $\underline{7}, 29-36$.

(46) Vesilind, P. The Rosin-Rammler particle size distribution. Resource Recovery and Conservation 1980, 5, 275-277, DOI: 10.1016/0304-3967(80)90007-4.

(47) HOTDISC ${ }^{\circledR}$ Combustion Device. http://www.flsmidth.com/en-US/Industries/ Categories/Products/Pyroprocessing/Hotdisc/Hotdisc, 2015; [accessed 05-Feb$2018]$.

(48) Willmarth, W.; Hawk, N.; Harvey, R. Steady and unsteady motions and wakes of freely falling disks. Physics of Fluids 1964, 7, 197-208.

(49) Komar, P.; Reimers, C. Grain shape effects on settling rates. Journal of Geology 1978, 86, 193-209, DOI: 10.1086/649674.

(50) Komar, P. Settling velocities of circular cylinders at low Reynolds numbers. Journal of Geology 1980, 88, 327-336, DOI: $10.1086 / 628510$. 


\section{Tables}

Table 1: The summary of RDF or SRF fuel samples properties tested in the current study.

\begin{tabular}{|c|c|c|c|c|c|c|}
\hline \multirow[b]{2}{*}{ RDF sample } & \multirow[b]{2}{*}{ place of use } & \multicolumn{5}{|c|}{ Fuel analysis ${ }^{1}$} \\
\hline & & $\begin{array}{l}\text { heating } \\
\text { value }^{1} \\
(\mathrm{MJ} / \mathrm{kg})\end{array}$ & $\begin{array}{l}\text { moisture } \\
\text { (wt.\%) }\end{array}$ & ash (wt.\%) & $\begin{array}{l}\text { volatiles } \\
(\text { wt.\%) }\end{array}$ & $\begin{array}{c}\text { fixed } \\
\text { carbon } \\
\text { (wt.\%) }\end{array}$ \\
\hline $\mathrm{RDF}-\mathrm{A}$ & Plant-1: calciner & 19.7 & 11.3 & 13.1 & 66.0 & 9.6 \\
\hline RDF-B & $\begin{array}{l}\text { Plant-2: calciner and kiln } \\
\text { main burner }\end{array}$ & 17.5 & 19.8 & 15.5 & 45.9 & 18.8 \\
\hline $\mathrm{RDF}-\mathrm{C}$ & Plant-3: kiln main burner & 31.4 & 1.5 & 6.0 & - & - \\
\hline $\mathrm{RDF}-\mathrm{D}$ & Plant-3: calciner & 18.7 & 17.3 & 12.5 & - & - \\
\hline RDF-E & Plant-3: calciner & 17.8 & 18.5 & 13.0 & - & - \\
\hline $\mathrm{RDF}-\mathrm{F}$ & Plant-2: HOTDISK ${ }^{\circledR}$ & 14.6 & 29.9 & 19.2 & - & - \\
\hline
\end{tabular}

1 The data are as-received basis. 
Table 2: The well-known literature correlations for the drag coefficient of non-spherical particles as a function of particle equivalent-volume diameter, $d_{p}$, sphericity, $\phi$, and the $\operatorname{Re}$ number.

\begin{tabular}{|c|c|c|}
\hline Author(s) & Correlation & Range of validity \\
\hline $\begin{array}{l}\text { Haider and Levenspiel } \\
(1989) \underline{25}\end{array}$ & $\begin{array}{l}C_{D}=\frac{24}{R e_{p}}\left(1+A R e_{p}^{B}\right)+\frac{C}{1+\frac{D}{R e_{p}}} \\
A=\exp \left(2.3288-6.4581 \phi+2.4486 \phi^{2}\right) \\
B=0.0964+0.5565 \phi \\
C=\exp \left(4.905-13.8944 \phi+18.4222 \phi^{2}-10.2599 \phi^{3}\right) \\
D=\exp \left(1.4681+12.2584 \phi-20.7322 \phi^{2}+15.8855 \phi^{3}\right) \\
\text { Simplified relation: } \\
C_{D}=\frac{24}{R e_{p}}\left[1+8.1716 \exp (-4.0655 \phi) R e_{p}^{0.0964+0.5565 \phi}\right]+\frac{73.69 R e_{p} \exp (-5.0748 \phi)}{R e_{p}+5.378 \exp (6.2122 \phi)}\end{array}$ & $\begin{array}{l}\operatorname{Re}<25,000 \text { and } \phi \geq 0.67 \\
\text { For } \phi<0.67 \text { the accuracy } \\
\text { is low }\end{array}$ \\
\hline Ganser $(1993)^{26}$ & $\begin{aligned} C_{D} & =k_{2}\left[\frac{24}{\operatorname{Re}_{p} K_{1} K_{2}}\left(1+0.1118\left(\operatorname{Re}_{p} K_{1} K_{2}\right)^{0.6567}\right)+\frac{0.4305}{1+\frac{3305}{\operatorname{Re}_{p} K_{1} K_{2}}}\right] \\
K_{1} & =\left(\frac{1}{3 \sqrt{\phi}}+\frac{2}{3 \sqrt{\phi}}\right)^{-1} \\
K_{2} & =10^{1.8148(-\log \phi)^{0.5743}}\end{aligned}$ & $\begin{array}{l}\text { Stokes and Newton region } \\
\text { and } \phi \geq 0.67\end{array}$ \\
\hline Chein $(1994)^{27}$ & $C_{D}=\frac{30}{R e_{p}}+\frac{67.289}{\exp (5.030 \phi)}$ & $\begin{array}{l}R e<5000 \text { and } 0.2<\Phi \leq \\
1\end{array}$ \\
\hline $\begin{array}{l}\text { Hartman } \\
(1994) \underline{28}\end{array}$ & $\begin{array}{l}C_{D}\left(R e_{p}, \phi\right)=C_{D}\left(\operatorname{Re}_{p}, 1\right) \times 10^{P\left(R e_{p}, \phi\right)} \\
C_{D}\left(R e_{p}, 1\right)=\frac{24}{\operatorname{Re}_{p}}\left(1+0.173 \operatorname{Re}_{p}^{0.657}\right) \frac{0.413}{1+16300 R e_{p}^{-1.09}} \\
P\left(\operatorname{Re}_{p}, \phi\right)=-0.03874(1-\phi) \log (\operatorname{Re} p)+0.09238(1-\phi)\left(\log \left(\operatorname{Re}_{p}\right)\right)^{2} \\
+0.06003(1-\phi)\left(\log \left(\operatorname{Re}_{p}\right)\right)^{3}+0.01005(1-\phi)\left(\log \left(\operatorname{Re}_{p}\right)\right)^{4} \\
-0.003571(1-\phi)\left(\log \left(\operatorname{Re}_{p}\right)\right)^{5}-0.005697(1-\phi)^{2}\left(\log \left(\operatorname{Re}_{p}\right)\right)^{5}\end{array}$ & $R e<16,000$ and $\phi \geq 0.67$ \\
\hline $\begin{array}{l}\text { Hölzer and Sommer- } \\
\text { feld }(2008)^{29}\end{array}$ & $\begin{array}{l}C_{D}=\frac{8}{R e_{p} \sqrt{\Phi_{\|}}}+\frac{16}{R e_{p} \sqrt{\Phi}}+\frac{3}{\Phi^{3 / 4} \sqrt{R e_{p}}}+\frac{0.4210^{0.4(-\log (\Phi))^{0.2}}}{\Phi \perp} \\
\Phi_{\perp}=\frac{\frac{\pi}{4} d_{p}^{2}}{\left(A_{p}\right)_{\perp}} \\
\Phi_{\|}=\frac{\frac{\pi}{4} d_{p}^{2}}{\frac{\pi d_{p}^{2}}{2 \phi}-\left\langle\left(A_{p}\right)_{\|}\right\rangle}\end{array}$ & $\begin{array}{l}\text { All ranges of Reynolds } \\
\text { numbers (except for the } \\
\text { boundary layer separation } \\
\text { region) and } \phi\end{array}$ \\
\hline
\end{tabular}

${ }^{*}\left(A_{p}\right)_{\perp}$ and $\left(A_{p}\right)_{\|}$are particle projected area normal and parallel to the direction of relative velocity, respectively. 
Table 3: The $d_{m}$ and $n$ values of Rosin-Rammler distribution for RDF-A and RDF-B fuel particles and each separated group from the wind sieve experiment.

\begin{tabular}{lcccc}
\hline \multicolumn{5}{c}{$d_{m}(m g) / n$} \\
\multicolumn{4}{c}{ Biomass } \\
velocity range \\
$(m / s)$ & RDF-A & RDF-B & RDF-A & RDF-B \\
\hline$<2$ & & & & \\
\hline $2-3$ & $20.2 / 1.61$ & $9.3 / 1.35$ & $16.9 / 1.51$ & $8.3 / 1.54$ \\
$3-5$ & $102.4 / 1.50$ & $31.3 / 1.62$ & $99.3 / 1.50$ & $44.2 / 1.43$ \\
$5-7$ & $330.5 / 1.92$ & $114.3 / 1.57$ & $410.7 / 1.65$ & $201.9 / 1.37$ \\
$>7$ & $874.9 / 1.89$ & $844.1 / 1.77$ & $785.8 / 1.68$ & $565.8 / 1.63$ \\
\hline
\end{tabular}

Table 4: The summary of the trend lines slope of scatter plots in Figs. 8 and 9.

\begin{tabular}{|c|c|c|c|c|c|c|}
\hline \multirow{3}{*}{$\begin{array}{l}\text { Terminal } \\
\text { velocity } \\
\text { range } \\
(\mathrm{m} / \mathrm{s})\end{array}$} & \multicolumn{5}{|c|}{ Trend line slope from curve $\left(\mathrm{mm}^{2} / \mathrm{mg}\right)$} & \multirow{3}{*}{ Std. dev. } \\
\hline & biomass & plastic & biomass & plastic & \multirow{2}{*}{ average } & \\
\hline & $\mathrm{RDF}-\mathrm{A}$ & $\mathrm{RDF}-\mathrm{A}$ & $\mathrm{RDF}-\mathrm{B}$ & $\mathrm{RDF}-\mathrm{B}$ & & \\
\hline$<2$ & 10.84 & 12.99 & 10.66 & 13.43 & 11.98 & 1.43 \\
\hline $2-3$ & 5.21 & 7.40 & 4.35 & 5.97 & 5.73 & 1.29 \\
\hline $3-5$ & 2.27 & 3.45 & 3.23 & 3.71 & 3.17 & 0.63 \\
\hline $5-7$ & 1.11 & 1.12 & 1.23 & 1.01 & 1.12 & 0.09 \\
\hline$>7$ & 0.60 & 0.49 & 0.46 & 0.47 & 0.51 & 0.07 \\
\hline
\end{tabular}


Table 5: The mass-weighted averages of sphericity of particles for RDF-A and RDF-B fuel samples and for each separated group from the wind sieve experiment.

\begin{tabular}{lllll}
\hline & \multicolumn{2}{c}{ Biomass } & \multicolumn{2}{c}{ Plastic } \\
velocity range & & & & \\
$(\mathrm{m} / \mathrm{s})$ & RDF-A & RDF-B & RDF-A & RDF-B \\
\hline$<2 \mathrm{~m} / \mathrm{s}$ & 0.14 & 0.15 & 0.09 & 0.10 \\
$2-3 \mathrm{~m} / \mathrm{s}$ & 0.23 & 0.28 & 0.12 & 0.15 \\
$3-5 \mathrm{~m} / \mathrm{s}$ & 0.31 & 0.39 & 0.21 & 0.26 \\
$5-7 \mathrm{~m} / \mathrm{s}$ & 0.41 & 0.49 & 0.33 & 0.39 \\
$>7 \mathrm{~m} / \mathrm{s}$ & 0.50 & 0.60 & 0.52 & 0.55 \\
\hline
\end{tabular}

Table 6: The mass-weighted average of terminal velocity of RDF particles predicted from the current proposed drag model as well as the existing literature models. For most of the literature drag models, the particle sphericity is outside of the range of validity of the model.

\begin{tabular}{|c|c|c|c|c|c|}
\hline \multirow[b]{2}{*}{ Drag model } & \multicolumn{5}{|c|}{$\begin{array}{l}\text { Mass-weighted averaged predicted terminal velocity }(\mathrm{m} / \mathrm{s}) / \\
\text { deviation from the mid-point velocity }{ }^{1}(\%)\end{array}$} \\
\hline & $V_{t}<2 \mathrm{~m} / \mathrm{s}$ & $V_{t}=2-3 \mathrm{~m} / \mathrm{s}$ & $V_{t}=3-5 \mathrm{~m} / \mathrm{s}$ & $V_{t}=5-7 \mathrm{~m} / \mathrm{s}$ & $V_{t}>7 \mathrm{~m} / \mathrm{s}$ \\
\hline Proposed method & $1.54 /-13.6$ & $2.43 /-2.8$ & $3.98 /-0.5$ & $6.04 /+0.6$ & $8.87 /+3.1$ \\
\hline Haider and Levenspiel ${ }^{25}$ & $2.25 /+28.6$ & $2.63 /+5.2$ & $3.33 /-16.8$ & $4.51 /-24.8$ & $6.23 /-27.5$ \\
\hline Ganser 26 & $1.09 /-37.7$ & $1.53 /-38.8$ & $2.38 /-40.5$ & $3.59 /-40.2$ & $5.42 /-37.0$ \\
\hline Chein 27 & $0.90 /-48.6$ & $1.16 /-53.6$ & $1.77 /-55.8$ & $2.76 /-53.9$ & $4.70 /-45.3$ \\
\hline Hartman et al. 28 & $2.35 /+34.3$ & $2.55 /+2.0$ & $2.87 /-28.3$ & $3.45 /-42.4$ & $4.67 /-45.7$ \\
\hline Hölzer and Sommerfeld 29 & $1.41 /-19.4$ & $1.98 /-20.8$ & $3.03 /-24.3$ & $4.53 /-24.4$ & $6.60 /-23.2$ \\
\hline
\end{tabular}

The mid-point velocities for velocity ranges of $<2 \mathrm{~m} / \mathrm{s}$ and $>7 \mathrm{~m} / \mathrm{s}$ are considered as 1.75 and $8.6 \mathrm{~m} / \mathrm{s}$, respectively. 
Table 7: The estimated values of $d_{m}$ and $n$ values of Rosin-Rammler distribution for RDF-A and $\mathrm{RDF}-\mathrm{B}$ fuel particles and each separated group from the wind sieve experiment. The error values are relative errors in comparison to the values in Table 3.

\begin{tabular}{|c|c|c|c|c|c|}
\hline \multirow[b]{3}{*}{$\begin{array}{l}\text { velocity range } \\
(\mathrm{m} / \mathrm{s})\end{array}$} & \multicolumn{5}{|c|}{$d_{m}(m g) / n$} \\
\hline & \multicolumn{2}{|c|}{ Biomass } & \multicolumn{2}{|c|}{ Plastic } & \multirow[b]{2}{*}{$\begin{array}{c}\text { Ave. } \\
\text { error }(\%)\end{array}$} \\
\hline & $\mathrm{RDF}-\mathrm{A}$ & RDF-B & $\mathrm{RDF}-\mathrm{A}$ & $\mathrm{RDF}-\mathrm{B}$ & \\
\hline$<2 \mathrm{~m} / \mathrm{s}$ & $20.3 / 1.89$ & $9.1 / 1.65$ & $23.0 / 1.69$ & $13.1 / 1.73$ & $24.2 / 16.0$ \\
\hline $2-3 \mathrm{~m} / \mathrm{s}$ & $25.8 / 2.04$ & $17.2 / 1.70$ & $57.4 / 1.79$ & $25.9 / 1.56$ & $15.3 / 11.6$ \\
\hline $3-5 \mathrm{~m} / \mathrm{s}$ & $88.7 / 1.62$ & $39.2 / 1.73$ & $118.3 / 1.75$ & $53.9 / 1.76$ & $19.9 / 13.7$ \\
\hline $5-7 \mathrm{~m} / \mathrm{s}$ & $338.8 / 2.02$ & $130.2 / 1.59$ & $398.8 / 1.80$ & $176.5 / 1.41$ & $8.0 / 4.6$ \\
\hline$>7 \mathrm{~m} / \mathrm{s}$ & $983.7 / 2.06$ & $700.0 / 1.98$ & $695.6 / 1.86$ & 493.9/1.71 & $13.4 / 8.9$ \\
\hline
\end{tabular}




\section{Figure Captions}

Figure 1. A schematic configuration of how the wind sieve setup is used for aerodynamic separation of RDF particles.

Figure 2. The camera setup used for taking 2D pictures from individual RDF particles.

Figure 3. Flowchart summarizing the process of RDF sample preparation, experimental methods and tests, and drag model studies and development (rectangle: process, parallelogram: data, diamond: decision).

Figure 4. The time-averaged velocity distribution of the air flow inside the wind sieve along a diameter at a cross-section upstream of the particle feed.

Figure 5. The mass-based cumulative distribution of the wind sieve experiment for different RDF samples mentioned in Table 1. The wind sieve set-point velocities may not be the same for all experiments.

Figure 6. The distribution of material composition for RDF-A and RDF-B samples after the wind sieve experiment and manual separation for wind sieve groups with terminal velocity ranges of $<2,2-3,3-5,5-7$, and $>7 \mathrm{~m} / \mathrm{s}$.

Figure 7. The measured distribution (symbols) as well as the Rosin-Rammler distribution (solid lines) of the mass of particles for the plastic and biomass fractions of RDF-A and RDF-B samples belonging to the wind sieve groups with terminal velocity ranges of $<2,2-$ $3,3-5,5-7$, and $>7 \mathrm{~m} / \mathrm{s}$. The dashed lines show the estimated mass distribution of particles described in section 4.5 .

Figure 8. The scatter distribution of biomass particles mass versus maximum projected area for $\mathrm{RDF}-\mathrm{A}$ and $\mathrm{RDF}-\mathrm{B}$ fuel samples belonging to the wind sieve groups with terminal velocity ranges of $<2,2-3,3-5,5-7$, and $>7 \mathrm{~m} / \mathrm{s}$.

Figure 9. The scatter distribution of plastic particles mass versus maximum projected area for $\mathrm{RDF}-\mathrm{A}$ and $\mathrm{RDF}-\mathrm{B}$ fuel samples belonging to the wind sieve groups with terminal velocity ranges of $<2,2-3,3-5,5-7$, and $>7 \mathrm{~m} / \mathrm{s}$. 
Figure 10. The scatter distribution of sphericity versus mass of particles for biomass and plastic fractions of $\mathrm{RDF}-\mathrm{A}$ and $\mathrm{RDF}-\mathrm{B}$ belonging to the wind sieve groups with terminal velocity ranges of $<2,2-3,3-5,5-7$, and $>7 \mathrm{~m} / \mathrm{s}$.

Figure 11. The scatter distribution of particle terminal velocity predicted by Eq. (8) versus particle mass for plastic and biomass fractions of RDF-A and RDF-B belonging to the wind sieve groups with terminal velocity ranges of $<2,2-3,3-5,5-7$, and $>7 \mathrm{~m} / \mathrm{s}$. The thick lines show the limits of terminal velocity for each wind sieve group.

Figure 12. The biomass fractions of RDF-A belonging to the wind sieve groups with terminal velocity ranges of $<2,2-3,3-5,5-7$, and $>7 \mathrm{~m} / \mathrm{s}$.

Figure 13. The plastic fractions of RDF-A belonging to the wind sieve groups with terminal velocity ranges of $<2,2-3,3-5,5-7$, and $>7 \mathrm{~m} / \mathrm{s}$.

Figure 14. The textile fraction of RDF-A belonging to the wind sieve groups with terminal velocity ranges of $<2,2-3,3-5,5-7$, and $>7 \mathrm{~m} / \mathrm{s}$.

Figure 15. The fine fraction of $\mathrm{RDF}-\mathrm{A}$ belonging to the wind sieve groups with terminal velocity ranges of $<2,2-3,3-5,5-7$, and $>7 \mathrm{~m} / \mathrm{s}$.

Figure 16. The inert fraction of RDF-A belonging to the wind sieve groups with terminal velocity ranges of $<2,2-3,3-5,5-7$, and $>7 \mathrm{~m} / \mathrm{s}$. 


\section{Figures}

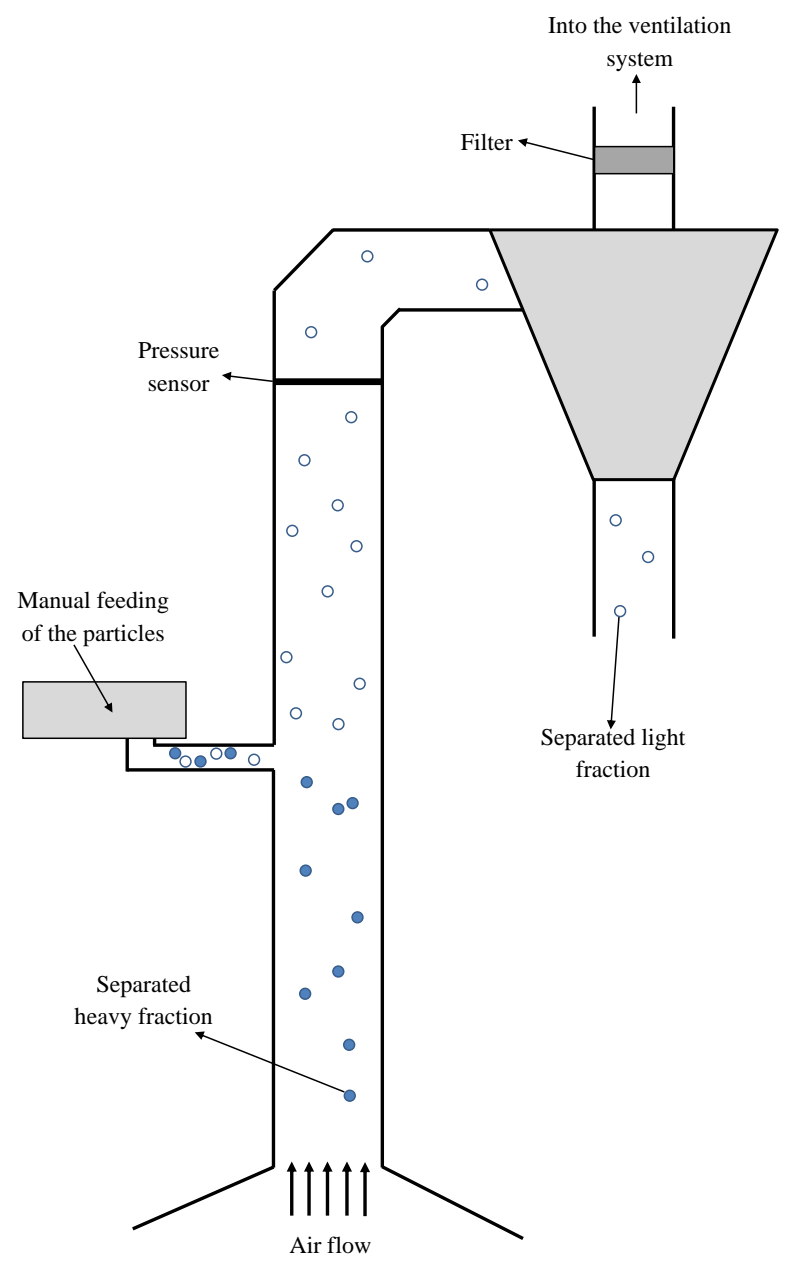

Figure 1: A schematic configuration of how the wind sieve setup is used for aerodynamic separation of RDF particles. 


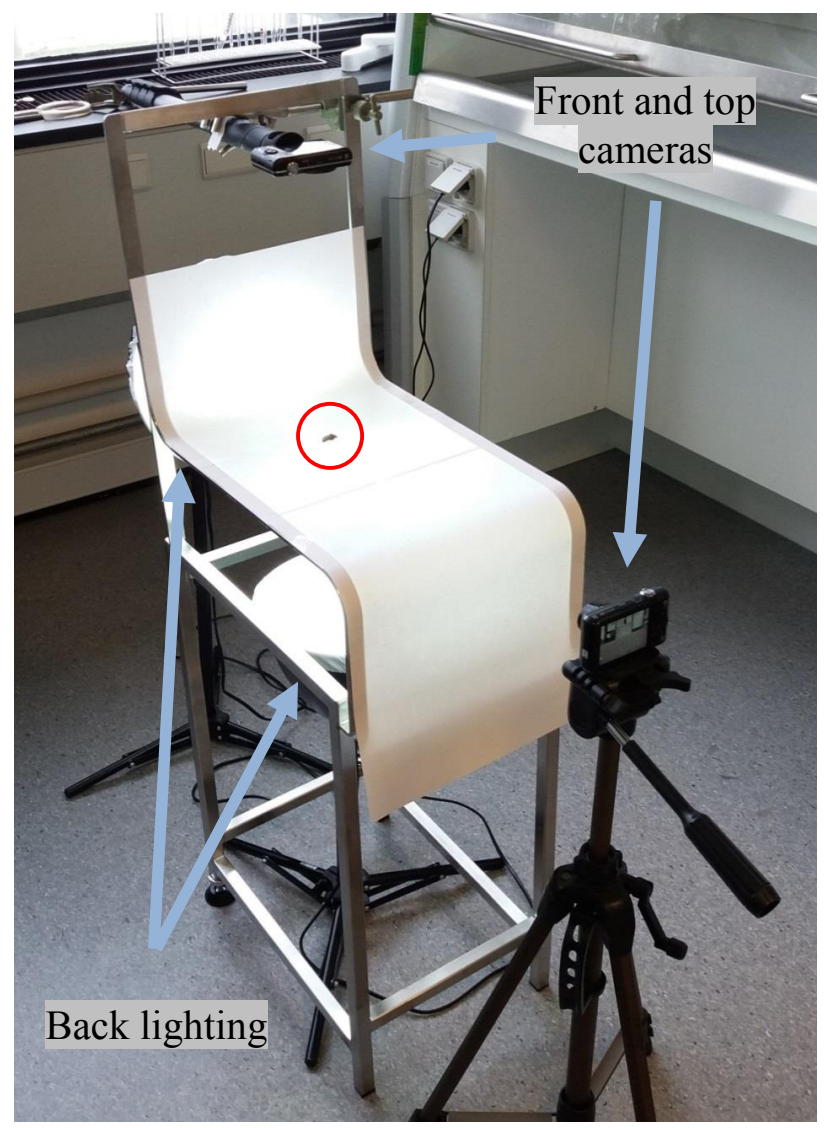

Figure 2: The camera setup used for taking 2D pictures from individual RDF particles. 


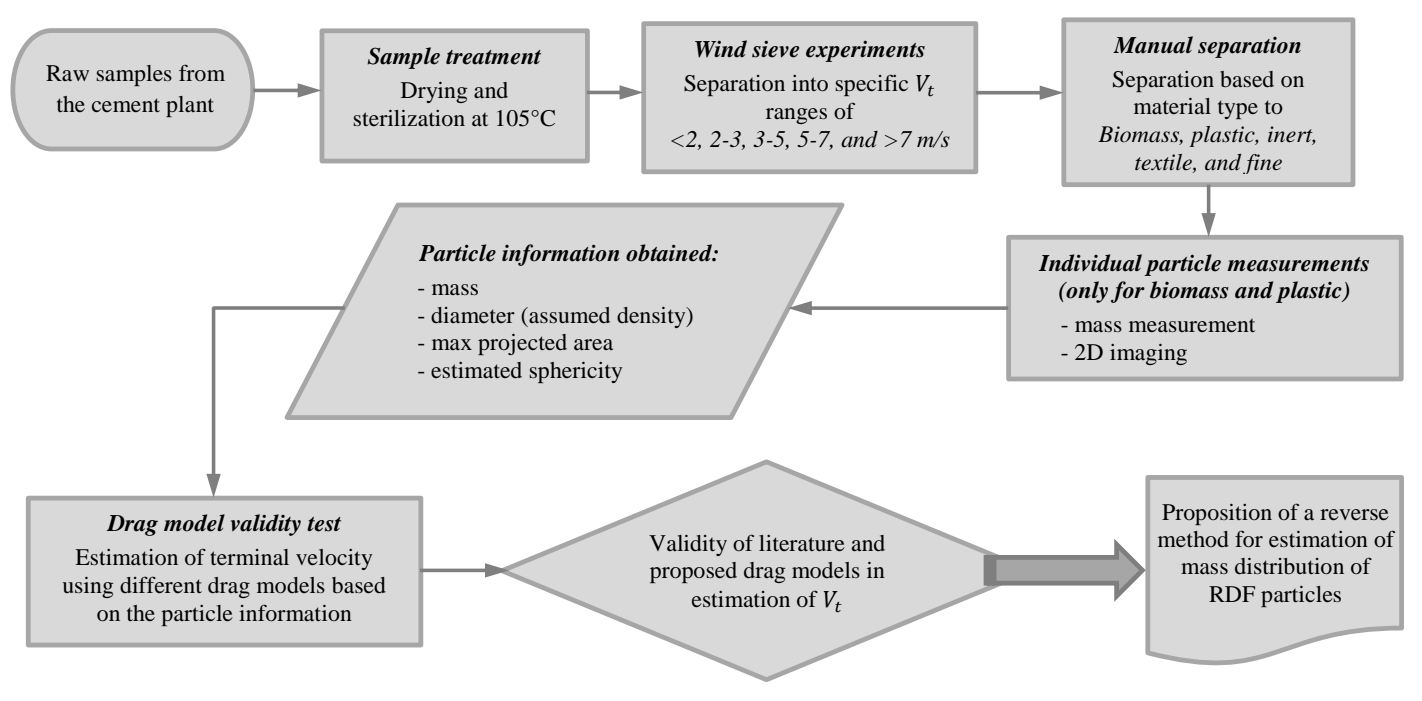

Figure 3: Flowchart summarizing the process of RDF sample preparation, experimental methods and tests, and drag model studies and development (rectangle: process, parallelogram: data, diamond: decision). 


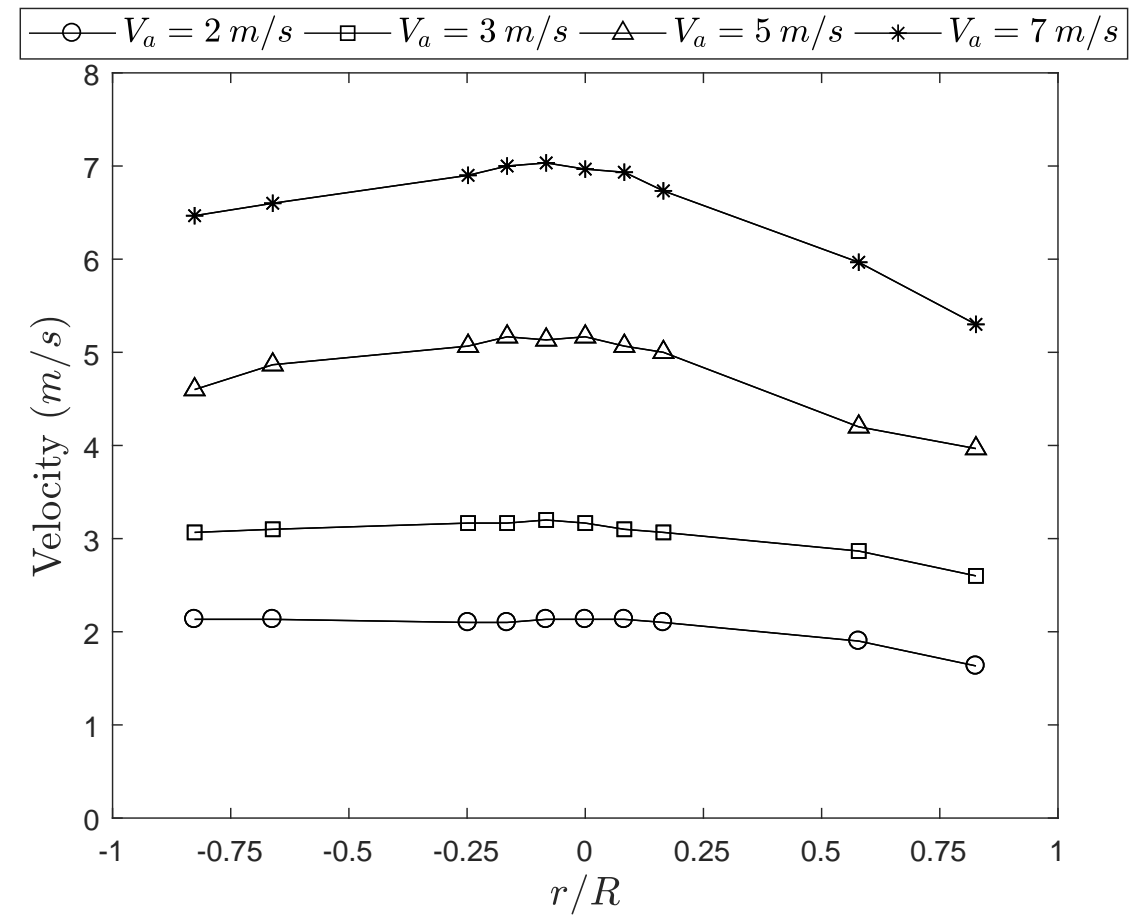

Figure 4: The time-averaged velocity distribution of the air flow inside the wind sieve along a diameter at a cross-section upstream of the particle feed. 


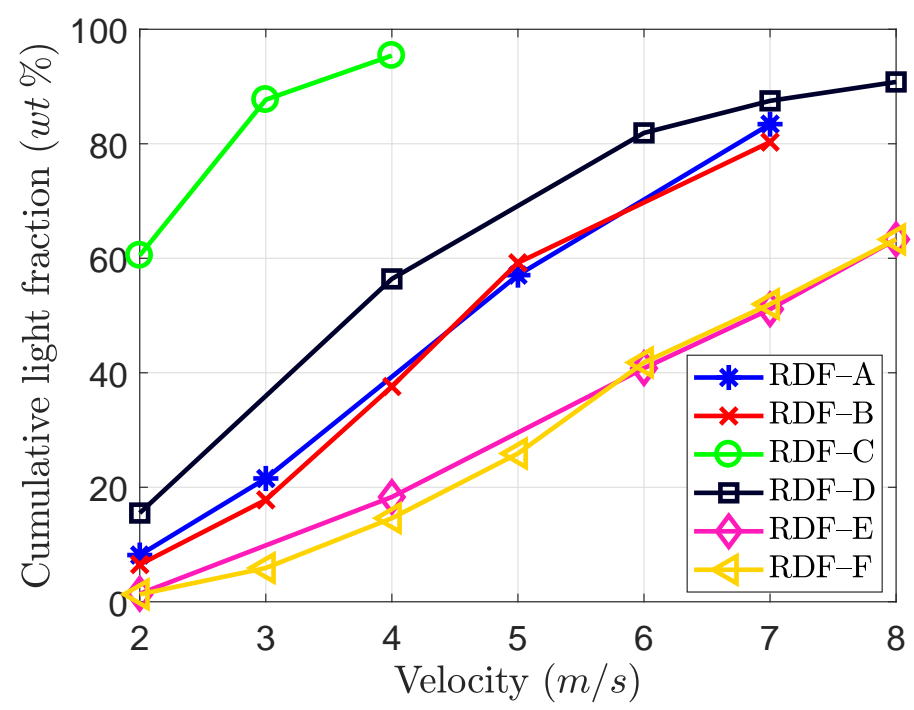

Figure 5: The mass-based cumulative distribution of the wind sieve experiment for different RDF samples mentioned in Table 1. The wind sieve set-point velocities may not be the same for all experiments.
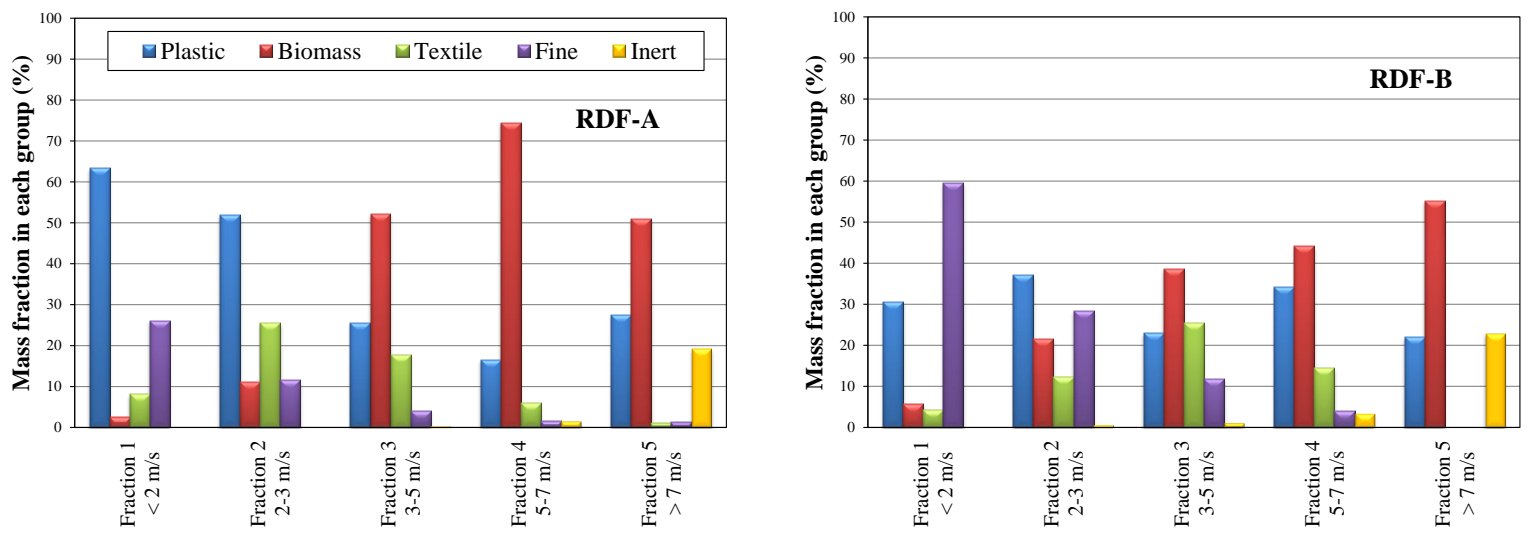

Figure 6: The distribution of material composition for $\mathrm{RDF}-\mathrm{A}$ and $\mathrm{RDF}-\mathrm{B}$ samples after the wind sieve experiment and manual separation for wind sieve groups with terminal velocity ranges of $<2,2-3,3-5,5-7$, and $>7 \mathrm{~m} / \mathrm{s}$. 

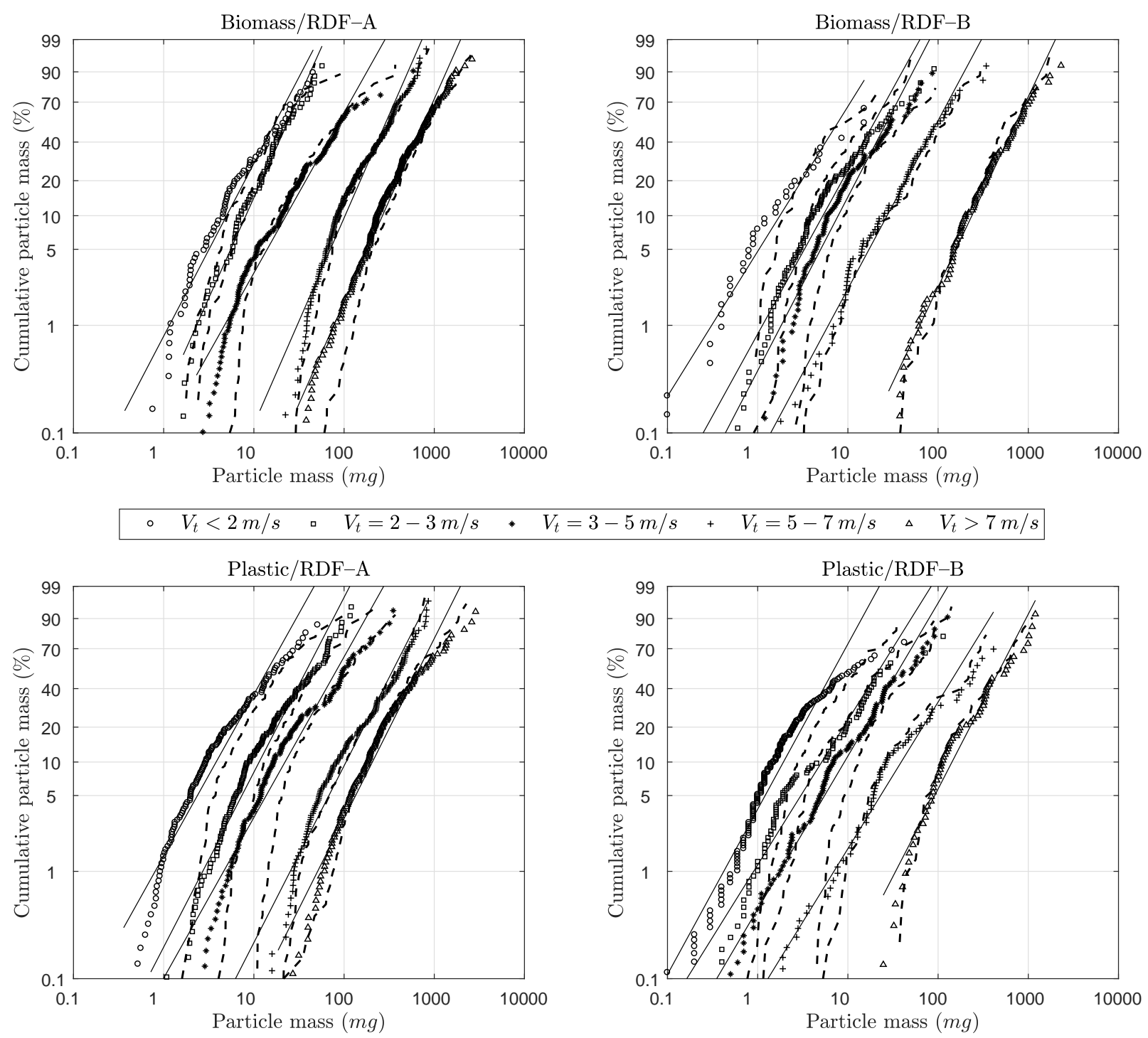

Figure 7: The measured distribution (symbols) as well as the Rosin-Rammler distribution (solid lines) of the mass of particles for the plastic and biomass fractions of RDF-A and RDF-B samples belonging to the wind sieve groups with terminal velocity ranges of $<2,2-$ $3,3-5,5-7$, and $>7 \mathrm{~m} / \mathrm{s}$. The dashed lines show the estimated mass distribution of particles described in section 4.5 . 

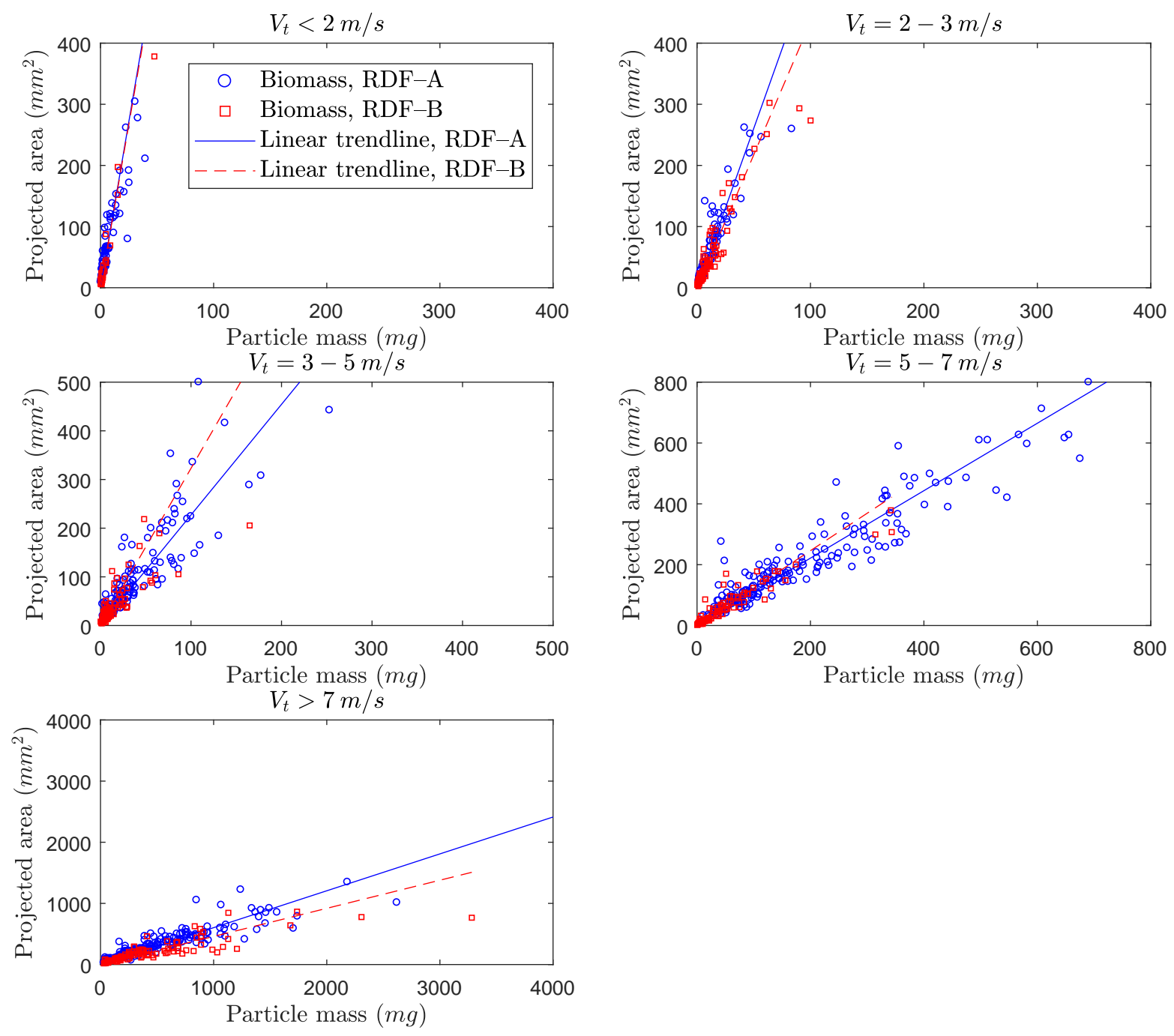

Figure 8: The scatter distribution of biomass particles mass versus maximum projected area for RDF-A and RDF-B fuel samples belonging to the wind sieve groups with terminal velocity ranges of $<2,2-3,3-5,5-7$, and $>7 \mathrm{~m} / \mathrm{s}$. 

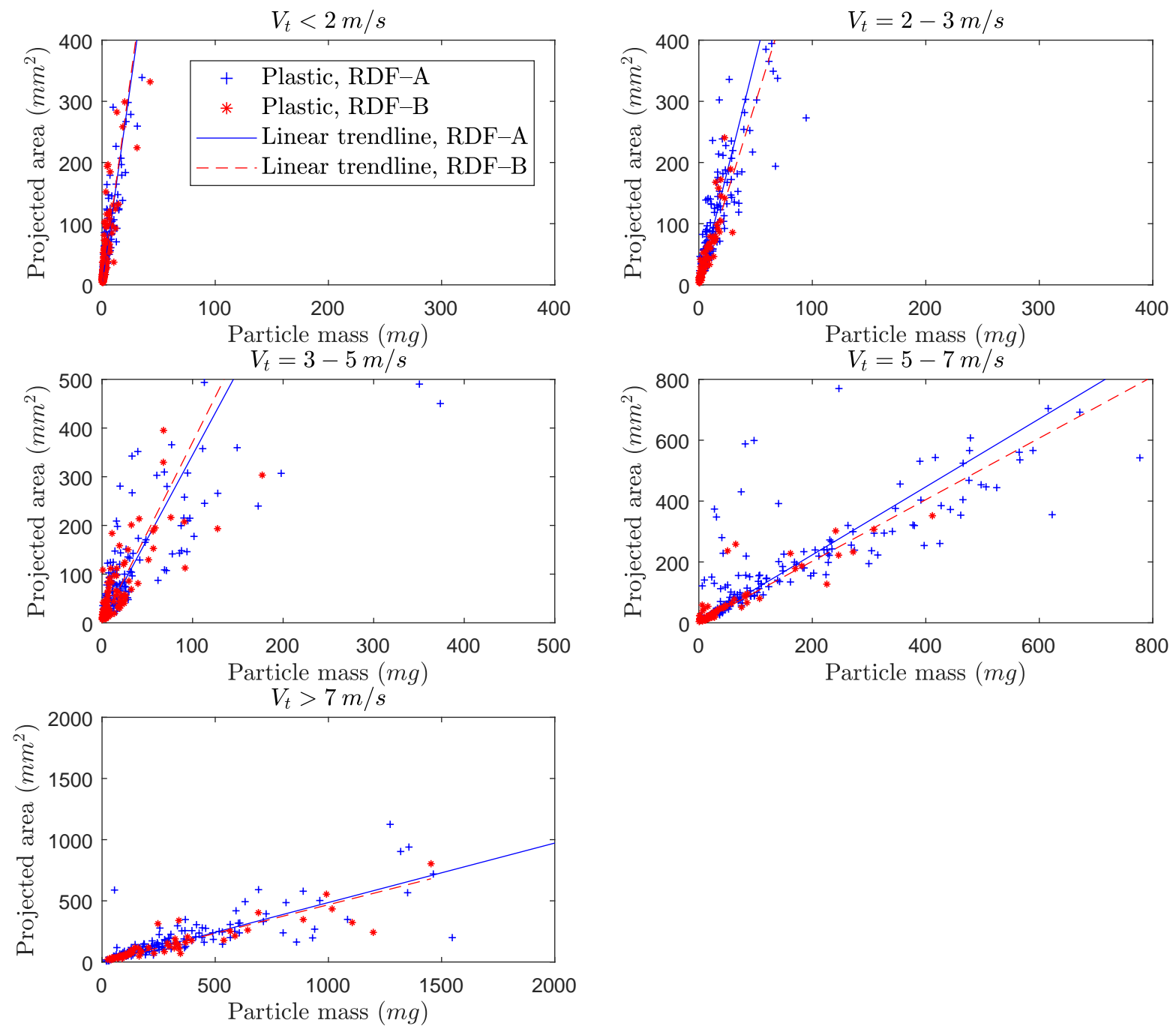

Figure 9: The scatter distribution of plastic particles mass versus maximum projected area for RDF-A and RDF-B fuel samples belonging to the wind sieve groups with terminal velocity ranges of $<2,2-3,3-5,5-7$, and $>7 \mathrm{~m} / \mathrm{s}$. 

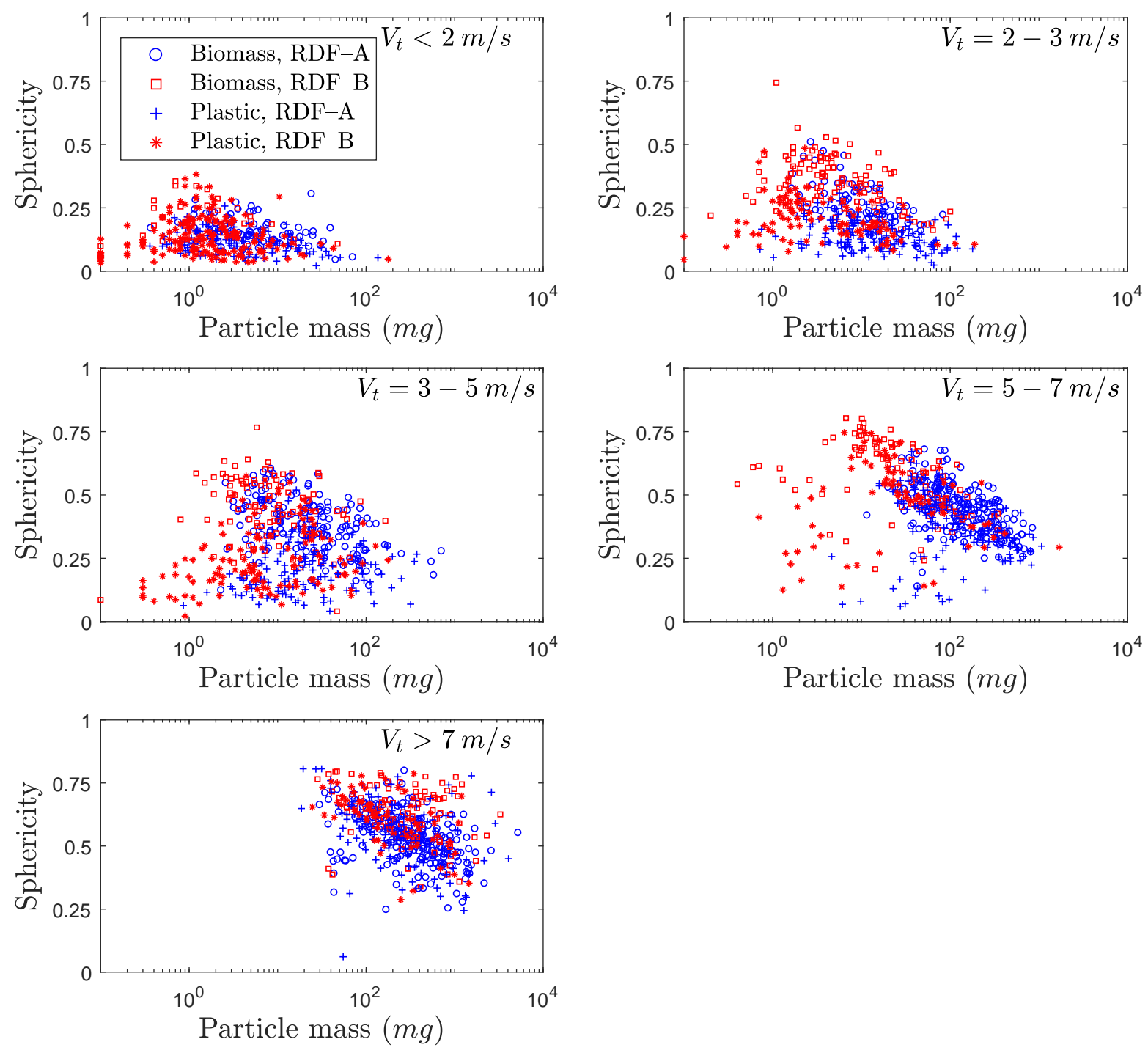

Figure 10: The scatter distribution of sphericity versus mass of particles for biomass and plastic fractions of $\mathrm{RDF}-\mathrm{A}$ and $\mathrm{RDF}-\mathrm{B}$ belonging to the wind sieve groups with terminal velocity ranges of $<2,2-3,3-5,5-7$, and $>7 \mathrm{~m} / \mathrm{s}$. 

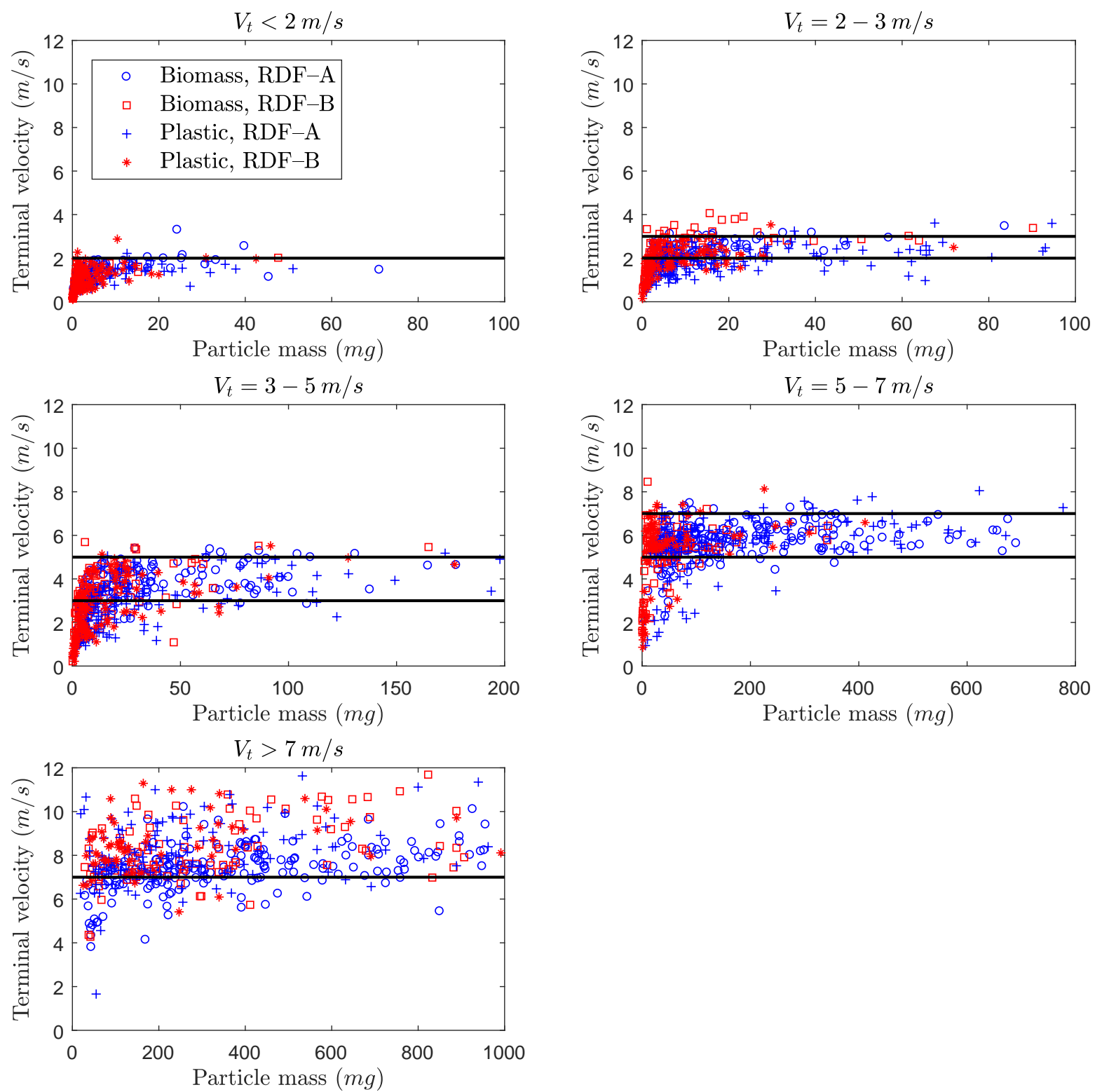

Figure 11: The scatter distribution of particle terminal velocity predicted by Eq. (8) versus particle mass for plastic and biomass fractions of RDF-A and RDF-B belonging to the wind sieve groups with terminal velocity ranges of $<2,2-3,3-5,5-7$, and $>7 \mathrm{~m} / \mathrm{s}$. The thick lines show the limits of terminal velocity for each wind sieve group. 


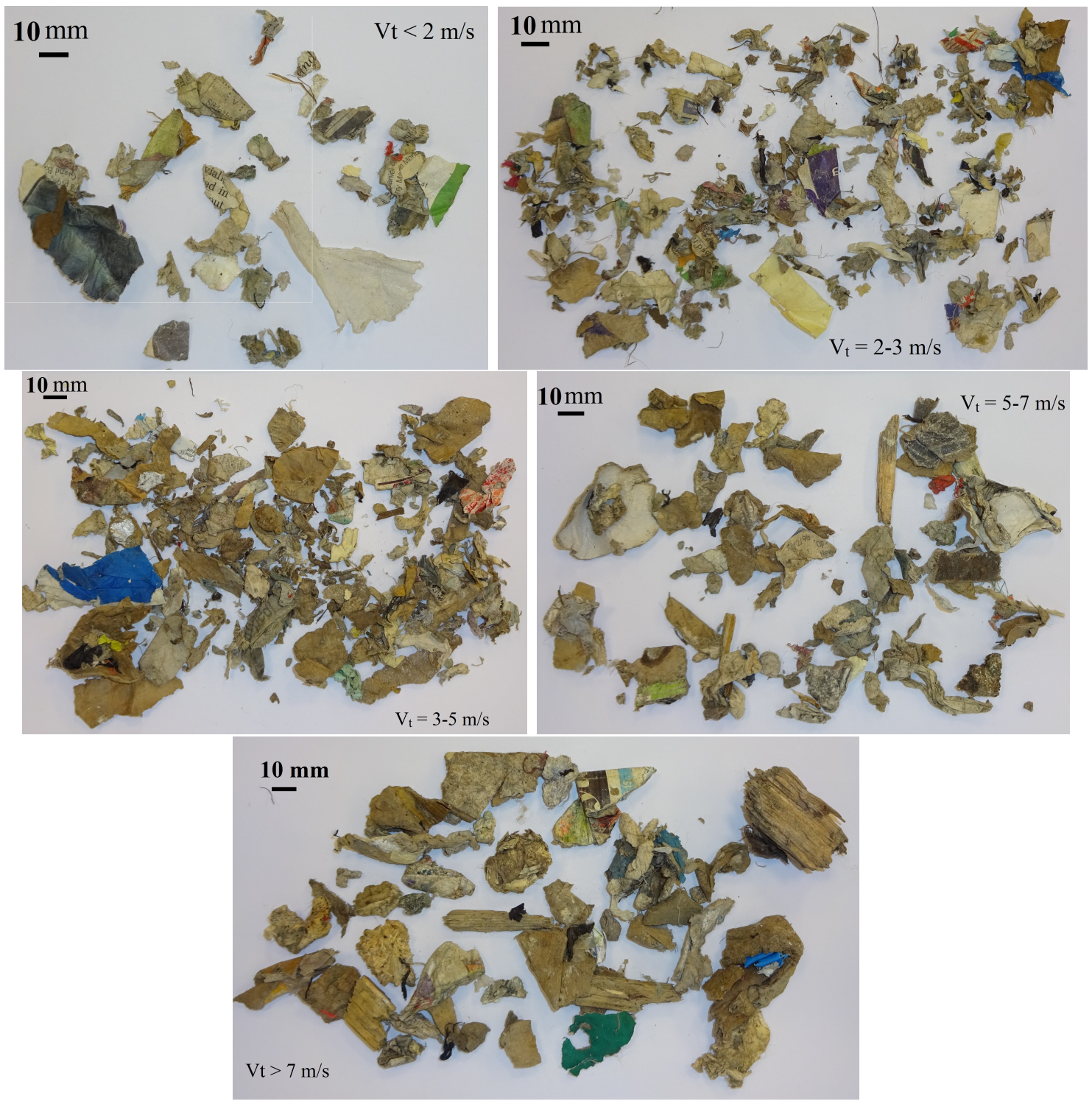

Figure 12: The biomass fractions of RDF-A belonging to the wind sieve groups with terminal velocity ranges of $<2,2-3,3-5,5-7$, and $>7 \mathrm{~m} / \mathrm{s}$. 


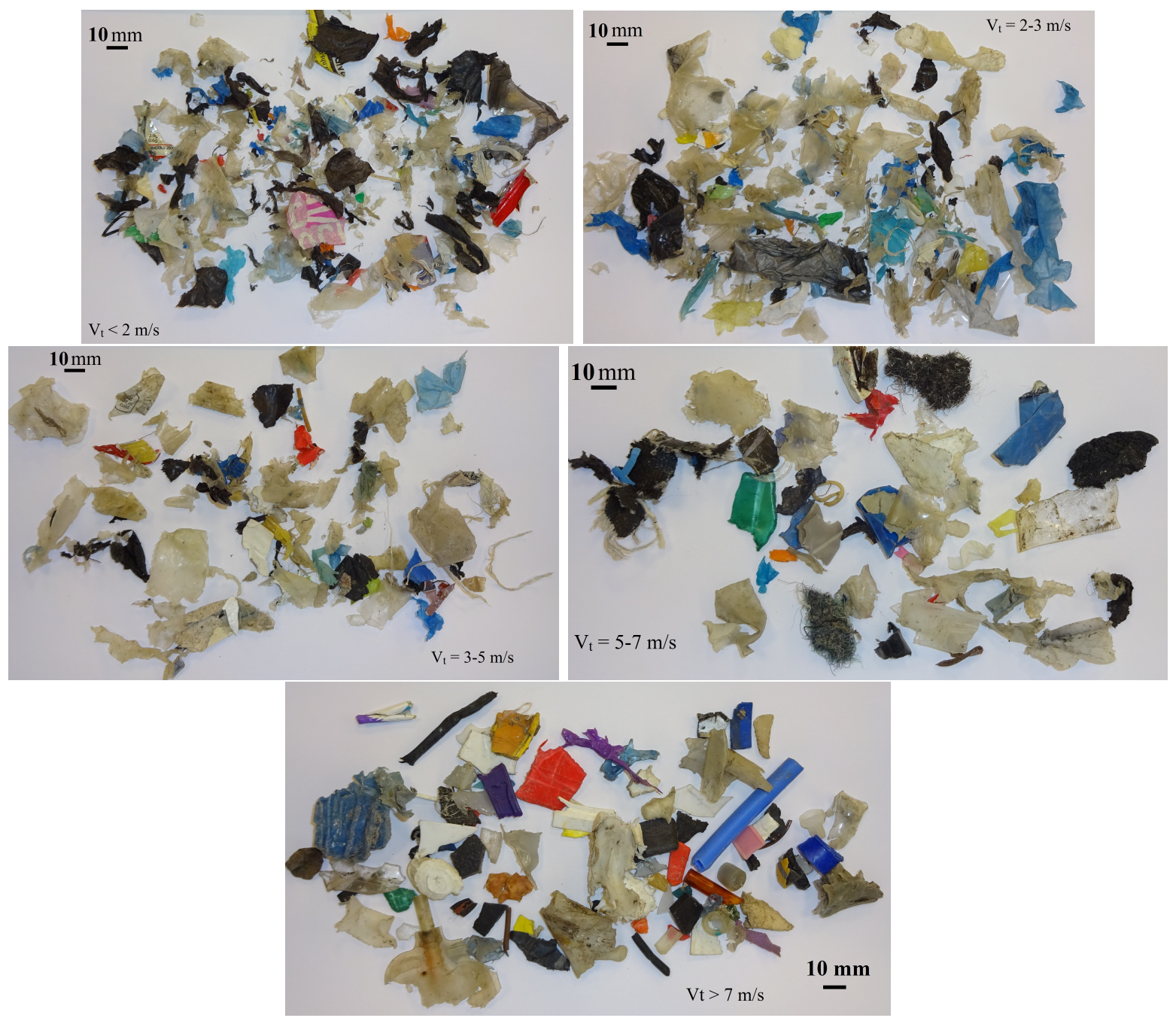

Figure 13: The plastic fractions of $\mathrm{RDF}-\mathrm{A}$ belonging to the wind sieve groups with terminal velocity ranges of $<2,2-3,3-5,5-7$, and $>7 \mathrm{~m} / \mathrm{s}$. 


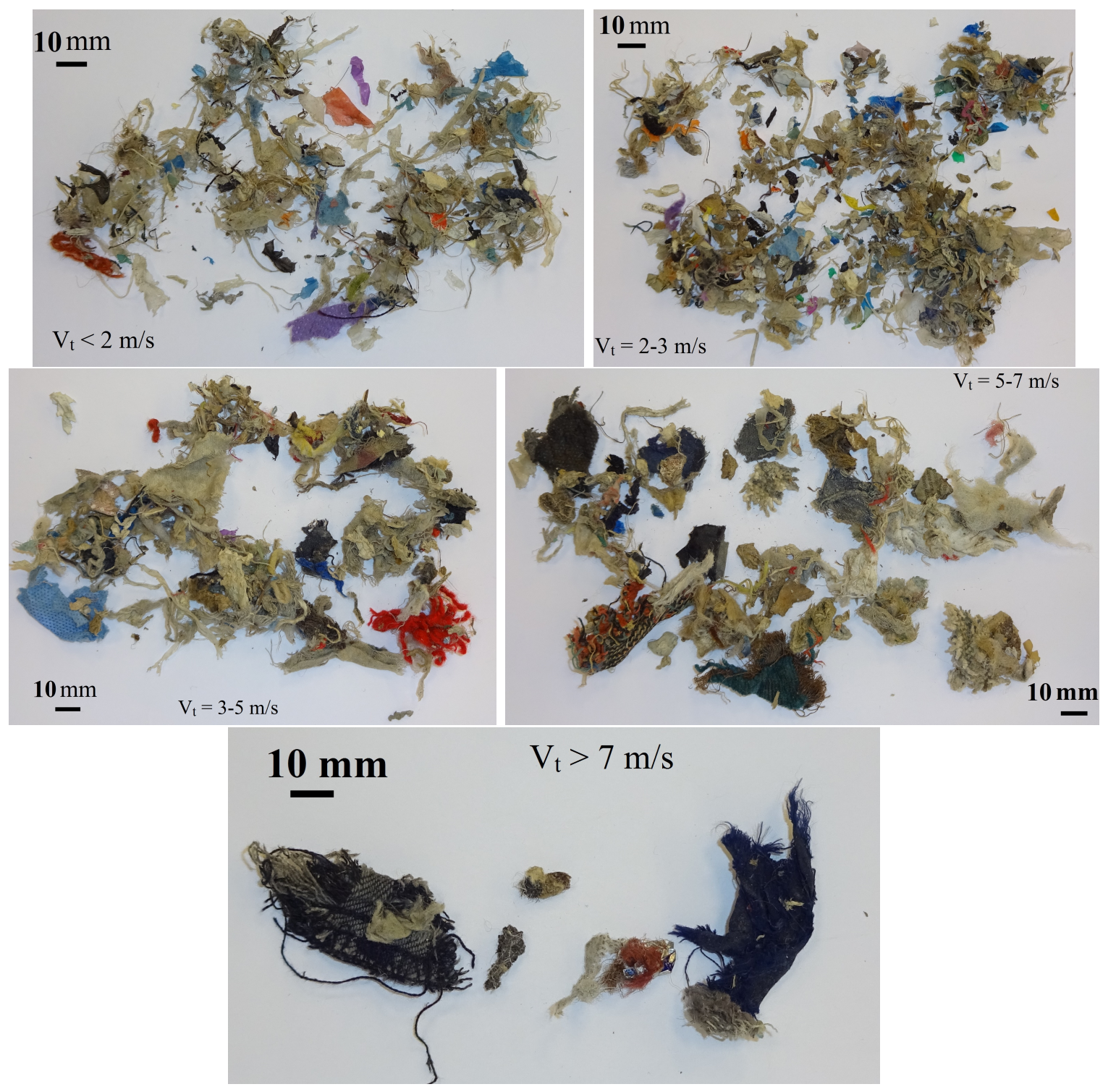

Figure 14: The textile fraction of $\mathrm{RDF}-\mathrm{A}$ belonging to the wind sieve groups with terminal velocity ranges of $<2,2-3,3-5,5-7$, and $>7 \mathrm{~m} / \mathrm{s}$. 


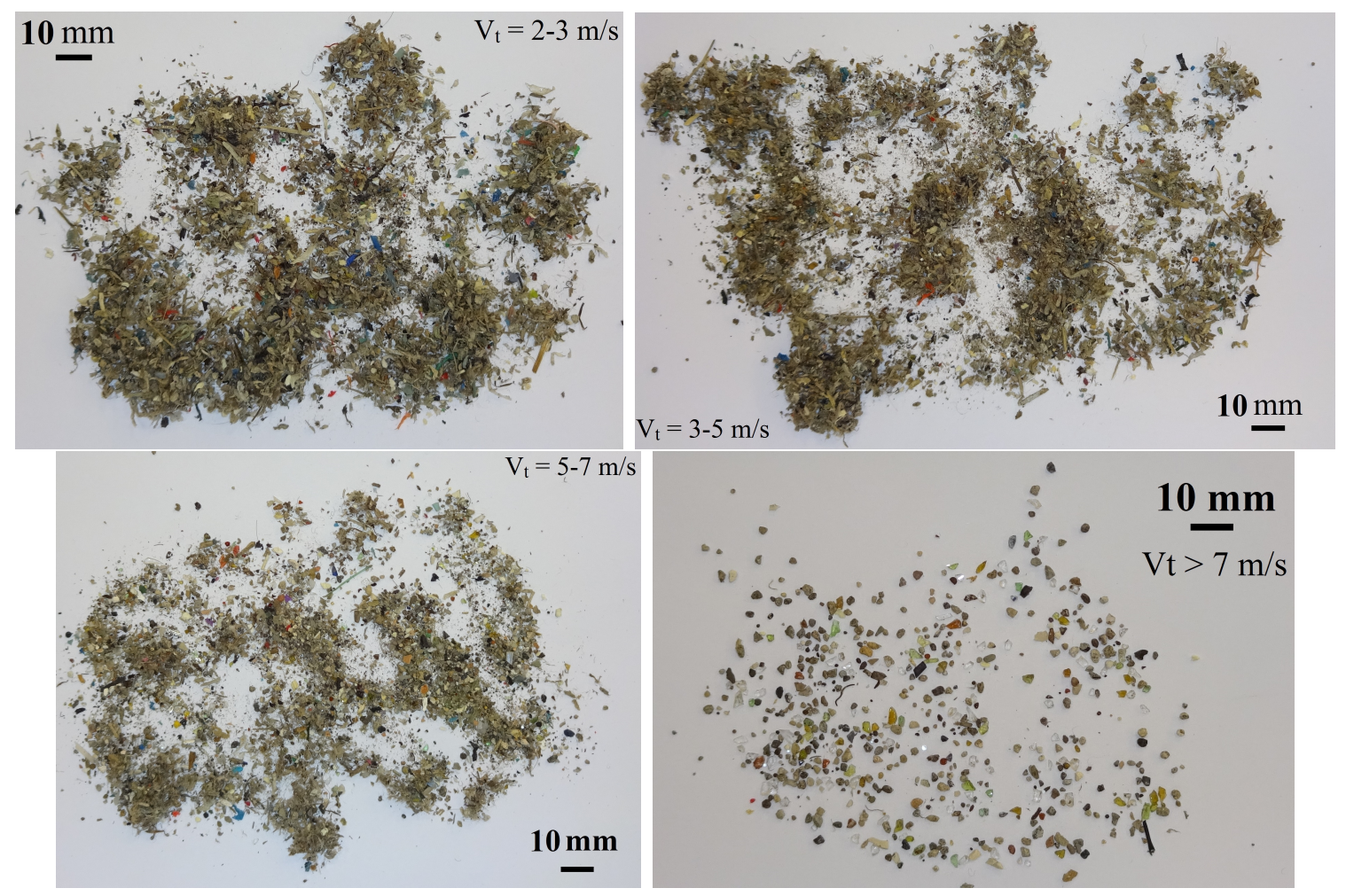

Figure 15: The fine fraction of $\mathrm{RDF}-\mathrm{A}$ belonging to the wind sieve groups with terminal velocity ranges of $<2,2-3,3-5,5-7$, and $>7 \mathrm{~m} / \mathrm{s}$. 


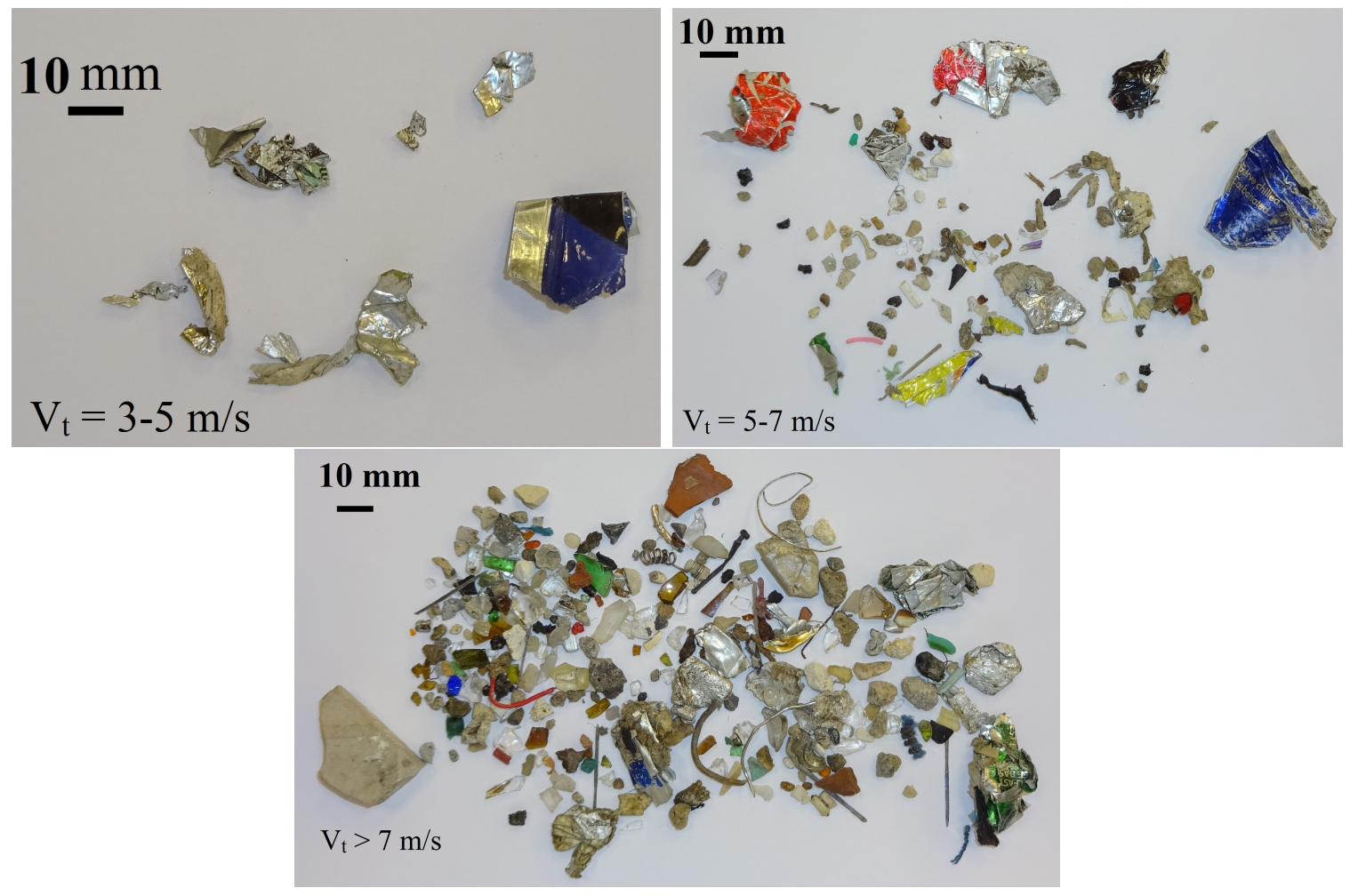

Figure 16: The inert fraction of $\mathrm{RDF}-\mathrm{A}$ belonging to the wind sieve groups with terminal velocity ranges of $<2,2-3,3-5,5-7$, and $>7 \mathrm{~m} / \mathrm{s}$. 